University of Rhode Island

DigitalCommons@URI

Open Access Master's Theses

1973

\title{
An Investigation of the Relationship Between the Sulfhydryl Activity and the Toxicity of a Series of Vinyl Sulfone Molluscicidal Agents
}

Paul Thomas La Rocca

University of Rhode Island

Follow this and additional works at: https://digitalcommons.uri.edu/theses

\section{Recommended Citation}

La Rocca, Paul Thomas, "An Investigation of the Relationship Between the Sulfhydryl Activity and the Toxicity of a Series of Vinyl Sulfone Molluscicidal Agents" (1973). Open Access Master's Theses. Paper 199.

https://digitalcommons.uri.edu/theses/199

This Thesis is brought to you for free and open access by DigitalCommons@URI. It has been accepted for inclusion in Open Access Master's Theses by an authorized administrator of DigitalCommons@URI. For more information, please contact digitalcommons-group@uri.edu. 


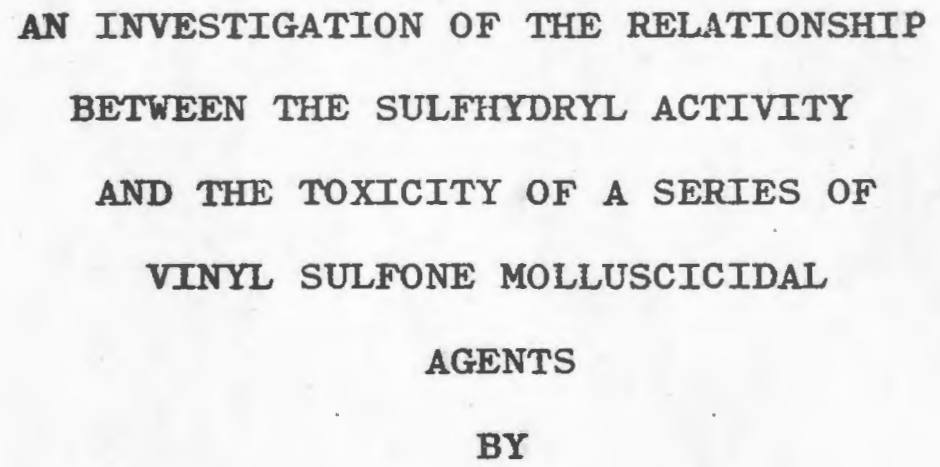
A THESIS SUBMITTED IN PARTIAL FULFILLMENT OF THE REQUIREMENTS FOR THE DEGREE OF


MASTER OF SCIENCE THESIS

OF

PAUL THOMAS LA ROCCA

\section{APPROVED:}

THESIS COMMITTEE:

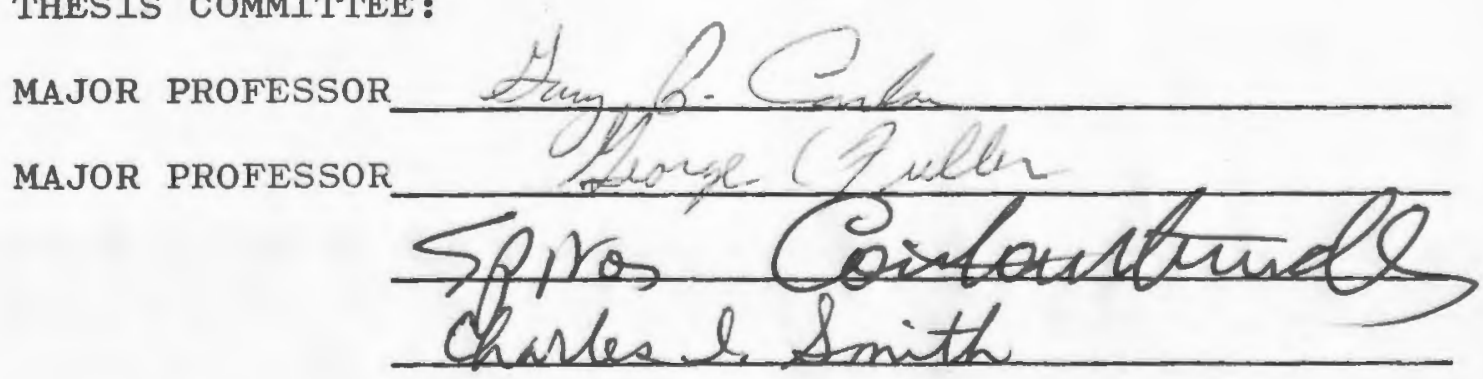

DEAN OF THE GRADUATE SCHOOL

\section{Q.l. humber}

UNIVERSITY OF RHODE ISLAND 


\section{ABSTRACT}

A series of vinyl sulfone molluscicidal agents was tested to determine the ability to interfere with: a) the color-forming reaction between cysteine and 5,5'-dithiobis (2-nitrobenzoic acid) (DTNB); b) the activity of malic dehydrogenase, a typical sulfhydryl-dependent enzyme; c) the in vitro endogenous respiration in the snail, Australoris glabratus; and d) the in vivo and in vitro endogenous respiration and pyruvate metabolism of liver, brain, and kidney of albino rats. An approximate intraperitoneal $\mathrm{LD}_{50}$ was determined for vinyl sulfone in male and female albino rats. The effect of vinyl sulfone on cysteine treated albino rats was also observed.

Vinyl sulfone and derivatives were found to inhibit the color-forming reaction between cysteine and DTNB indicating sulfhydryl reactivity. A positive correlation between this in vitro sulfhydryl reactivity and molluscicidal potency was observed. However, no significant effect on endogenous respiration was observed in A. glabratus. Similarly, no significant effects on endogenous respiration or pyruvate metabolism were observed in the tissues tested from male and female albino rats. High concentrations of vinyl sulfone vere required to significantly inhibit the activity of malic dehydrogenase. 
An intraperitoneal $\mathrm{LD}_{50}$ of $3 \mathrm{mg} / \mathrm{kg}$ vinyl sulfone was found for male and female albino rats. A sublethal dose of vinyl sulfone was found to cause increased blood urea nitrogen and decreased urinary output in albino rats while producing no significant effects on SGOT, SGPT, and hematocrit levels.

These data indicate that the toxicity of vinyl sulfone and derivatives is related to sulfhydryl reactivity; however, this toxicity was not due to decreased endogenous respiration in either $\underline{A}$. glabratus or albino rats. The toxicity of sublethal doses of vinyl sulfone was postulated to be caused by the impairment of normal renal function.

A hypothesis was proposed that the toxicity of vinyl sulfone and derivatives in A. glabratus may be due to the reaction of these agents with integral membrane proteins responsible for normal cellular function. 
I WOULD LIKE TO DEDICATE THIS WORK TO THE TWO FAMILIES WHO DONATED THE CORNEAS OF THEIR DECEASED LOVED ONES TO THE MANHATTAN EYE BANK. THEIR GENEROSITY, IN THE FACE OF DEATH, HAS MADE THIS RESEARCH POSSIBLE. 


\section{SPECIAL THANKS}

I would like to thank my wife, Mary Anne, for her love, understanding, and inspiration.

I would also like to thank my parents, Mr. and Mrs. Rudolph La Rocca, for their guidance and financial help.

I would also like to express my gratitude to $\mathrm{Dr}$. H. Katzin whose surgical skill has given me new sight. 


\section{ACKNOWLEDGEMENTS}

I would like to express my appreciation for the guidance provided by Dr. Gary P. Carlson and Dr. George C. Fuller.

The generosity of $\mathrm{Dr}$. H. Bond, who provided the snails used in this research, is gratefully acknowledged. I would also like to thank my fellow graduate students for their helpful suggestions.

Financial support for this investigation was supplied, in part, by the office of Water Resources Research, under PL 88-379, and the Department of Pharmacology and Toxicology, College of Pharmacy, University of Rhode Island. 
TABLE OF CONTENTS

Page

ACKNOWLEDGEMENTS

ABSTRACT .

iii

TABLE OF CONTENTS

LIST OF FIGURES.

I. INTRODUCTION

II. SURVEY OF THE LITERATURE..................

A. THE SEARCH FOR THE IDEAL MOLLUSCICIDE......

B. THE MODE OF ACTIVITY OF MOLLUSCICIDAL

AGENTS.

C. THE ROLE OF SULFHYDRYL GROUPS IN BIO-

LOGICAL PROCESSES. .................... 14

D. BIOCHEMICAL CHARACTERISTICS OF GASTROPODS...

E. THE MECHANISM OF ACTION OF BETA-NITROSTY-

RENES.

F. VINYL SULFONE: THE HISTORY AND RELATION-

SHIP BETWEEN VINYL SULFONE AND BETA-

NITROSTYRENE....................

III. EXPERIMENTAL........................

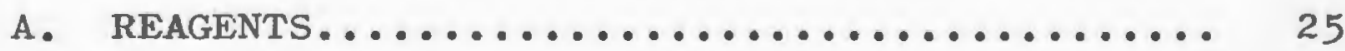

B. ANIMALS........................... 25

C. analytical PROCEdURES................. 26 
1. DETERMINATION OF SULFHYDRYL RE-

ACTIVITY. ..................

2. DETERMINATION OF MALIC DEHYDROGENASE ACTIVITY.

3. DETERMINATION OF IN VITRO ENDOGENOUS RESPIRATION IN A. GLABRATUS.........

4. DETERMINATION OF AN APPROXIMATE $\mathrm{LD}_{50}$ FOR VINYL SULFONE............... 28

5. PROTECTION STUDIES WITH CYSTEINE....... 28

6. DETERMINATION OF IN VITRO ENDOGENOUS RESPIRATION IN RAT TISSUE SLICES.....

7. DETERMINATION OF ENDOGENOUS RESPIRATION IN RAT BRATN SLICES OF FEMALE RATS TREATED IN VIVO WITH VINYL SULFONE...

8. DETERMINATION OF IN VITRO PYRUVATE METABOLISM IN LIVER AND BRAIN HOMOGENATES OF MALE RATS.......... 30

9. DETERMINATION OF PYRUVATE METABOLISM

IN LIVER, KIDNEY, AND BRAIN HOMOGENATES OF MALE RATS TREATED IN VIVO WITH VINYL SULFONE............. 31

10. DETERMINATION OF HEMATOCRIT LEVELS IN

MALE RATS..................... 32

11. BLOOD CHEMISTRIES AND URINE ANALYSES .. 32

a. DETERMINATION OF SGOT AND SGPT LEVELS. .................. 
Page

b. DETERMINATION OF BLOOD UREA

NITROGEN................... 33

c. DETERMINATION OF URINARY VOLUME,

pH, SUGAR AND PROTEIN......... 34

D. STATISTICAL METHODS.................. 35

IV. $\quad$ RESULTS............................. 38

A. SULFHYDRYL REACTIVITY.................. 38

B. ENZYME STUDIES........................ 46

c. OXYGEN UPTAKE STUDIES IN A. GLABRATUS AND

RAT TISSUE.......................... 50

D. $\mathrm{LD}_{50}$ AND PROTECTION STUDIES............. 57

E. HEMATOLOGY, BLOOD CHEMISTRIES AND URINE

ANALYSES............................... 58

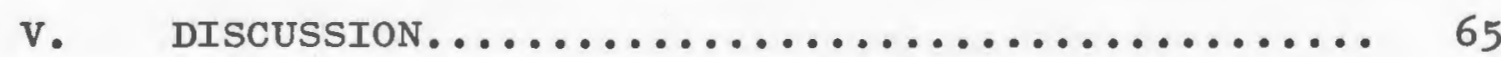

VI. SUMMARY AND CONCLUSIONS................... 74

VII. $\quad$ REFERENCES.............................. 75 


\section{LIST OF TABLES}

Table

Page

1. Effect of vinyl sulfone and derivatives on the color-forming reaction between DTNB and sulfhydryl groups of cysteine............. 41

2. Relationship between $\mathrm{EC}_{50}$ and sulfhydryl reactivity of vinyl sulfohe and derivatives.....4 43

3. Relationship between $\mathrm{EC}_{50}$ and sulfhydryl reactivity of $\mathrm{N}$-tritylmorpholine and $\mathrm{N}$-triphenylacetylmorpholine.................

4. Effect of vinyl sulfone on the activity of purified porcine malic dehydrogenase.........4 47

5. Effect of substrate concentration on the in vitro activity of purified porcine malic $\overline{\text { de- }}$ hydrogenase........................ 49

6. Effect of vinyl sulfone on the in vitro endogenous respiration of the snail, $A$. glabratus.

7. Effect of in vitro vinyl sulfone on endogenous respiration in liver and brain slices of female rats...................... 52

8. Endogenous respiration in brain slices of female rats treated in vivo with vinyl sulfone............................

9. Effect of in vitro vinyl sulfone on pyruvate metabolism in brain homogenates of male rats... 54

10. Effect of in vitro vinyl sulfone on pyruvate metabolism in liver homogenates of male rats... 55

11. Pyruvate metabolism in liver, kidney, and brain homogenates of male rats treated in vivo with vinyl sulfone................ 56

12. Determination of an approximate intraperitoneal $L_{50}$ for vinyl sulfone in female rats... 59 
Table

13. Determination of the effects of vinyl sulfone on male rats pretreated subcutaneously or intraperitoneally with cysteine hydrochloride...

14. Effect of vinyl sulfone on the hematocrit of male rats..........................

15. The hepatotoxicity of vinyl sulfone in female

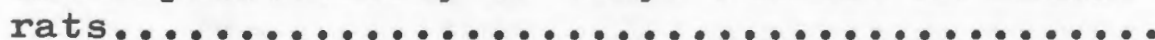

16. Effect of vinyl sulfone on hematocrit and kidney function of male rats............. 


\section{LIST OF FIGURES}

Figure

Page

1. Reaction of $5,5^{\prime}$ dithiobis(2-nitrobenzoic acid) with thiol compound............... 40

2. Recation of vinyl sulfone and derivatives with sulfhydryl groups of cysteine......... 42

3. Affinity of vinyl sulfone and derivatives for sulfhydryl groups of cysteine......... 45

4. Effect of vinyl sulfone, diethyl sulfone, and cysteine + vinyl sulfone on the in vitro activity of purified porcine malic dehydrogenase....................... 


\section{INTRODUCTION}

Schistosomiasis, the parasitic disease of man caused by the trematodes Schistosoma haematobium, Schistosoma mansoni, and Schistosoma japonicum, has plagued man since ear1y Egyptian times. In fact, large numbers of calcified ova of the parasite have been found in Egyptian mummies which date as far back as 1250 to 1000 B.C.. The incidence is high in Africa, Asia, South America, and the Philippines and it is estimated that at least 180-200 million people are infected (Jordan et al. 1969). Recent studies indicate that this number is increasing (Jordan et al. 1969).

Specific chemotherapy for the treatment of schistosomiasis is effective in the early stages of the disease. However, it is of little value and may even be dangerous in the advanced stages. This presents a major problem because most geographical areas affected by the disease are characterized by an agricultural population poor in resources, and thus early medical detection and care is impossible.

One approach in the attempt to control schistosomiasis has been eradication of the intermediary snail hosts through the use of molluscicides. The use of molluscicidal agents presents a number of uniquely difficult problems. Molluscicidal agents must be toxic in low concentrations to the molluscan host and, at the same time, non-toxic to man and 
domestic and wild animals. The agents should also be sufficiently soluble in water, inexpensive and easy to use. According to the World Health Organization (1965), progress in the control of schistosomiasis has been slow due to the failure to recognize its public health importance earlier, a dearth of basic data on the prevalence and transmission of the disease, the inadequacy of available control measures and slow progress in developing and evaluating new and better ones, the small number of trained personnel available, and the lack of money.

In recent years the importance of molluscicides as a means of controlling the snail vectors of schistosomiasis has been well established. Over the years the pesticide industry has developed numerous chemicals, certain of which possess molluscicidal properties. The basis, however, on which compounds are selected for testing as molluscicides remains largely empirical and any approach that enables selection to be made with a better understanding of molluscicidal activity would be an advance. The bulk of the data available concerning molluscicidal agents which are presently in use or in the last screening stages deals with mortality times and concentrations required for these results. Little information concerning the effects of the drug on man or animals is available and far less information is available concerning the mechanism of action of these compounds.

Elucidation of the mechanism of action of mollusci- 
cidal agents would provide a basis for the rational approach to production of new molluscicidal agents by providing the medicinal chemist with information concerning structurefunction relationships. Knowledge of structure-function relationships inherent in a series of compounds would, theoretically, enable the production of new compounds which would exert similar actions while exhibiting increased target specificity and decreased harmful effects to non-target organisms.

Recently, Louis-Ferdinand (1969) observed a correlation between the sulfhydryl reactivity of a series of nitroolefinic beta-nitrostyrenes and their ability to produce a decrease in oxygen uptake in Australorbis glabratus,

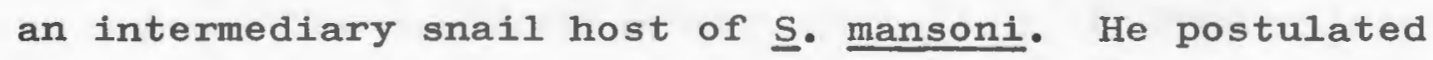
that the molluscicidal activity of these nitroolefins was due to their ability to react with and inhibit essential sulfhydryl-dependent enzymes of the metabolic pathways involved in the snail's respiratory system.

Vinyl sulfone has been shown to be a potent molluscicidal agent with a high degree of sulfhydryl reactivity. Vinyl sulfone also exhibits structural similarities to the nitroolefins studied by Louis-Ferdinand, and, therefore, it is of interest to determine if the sulfhydryl reactivity of vinyl sulfone is related to its toxicity and/or a decrease in oxygen uptake in snails and other test anima1s.

The studies to be described were designed to deter- 
mine: if vinyl sulfone inhibited respiration and other enzymatic processes; if there existed a correlation between the sulfhydryl reactivity of the vinyl sulfone series and their molluscicidal activities; if vinyl sulfone inactivated sulfhydryl dependent enzymes in vitro and finally, if vinyl sulfone, when given in low doses, produced any changes in selected parameters of rodent physiology. 


\section{SURVEY OF THE LITERATURE}

\section{A. THE SEARCH FOR THE IDEAL MOLLUSCICIDE}

The molluscicides that are presently available fall far short of the ideal. It appears justified, therefore, not only to continue the search for new molluscicides but also to examine the factors that might produce more specific molluscicides. In the past several years man has intensified his efforts to achieve these two goals.

Duncan and Pavlik (1971) screened fifty-one fluorinated aromatic compounds for molluscicidal activity against B. glabratus, one of the intermediary snail vectors of $\underline{S}$ mansoni. They found two compounds, tetrafluoroterephthalonitrile and tetrafluorophthalonitrile, were effective at concentrations ranging from $0.1 \mathrm{ppm}$ to $0.6 \mathrm{ppm}$ and were planning field trials in the near future. Jobin and Gladwin (1967) have screened twenty-eight molluscicidal compounds for their activity against $A$. glabratus. $2^{\prime}, 5^{\prime}$-Dichloro-4'-nitrosalicylanilide (Bayer 73), CuSO 4 , isobutyltriphenyl methylamine (ICI-24223), and 3-trifluoromethy1-4-nitrophenol (E1cide-TFM) were found to be the best. $2^{\prime}, 5^{\prime}$-Dichloro-4'-nitrosalicylanilide was the most toxic. N-Tritylmorpholine has been shown to possess outstanding molluscicidal activity (Boyce et al. 1966). devilliers .. (1963) has shown that phenacyl halides are also a potenti- 
ally excellent group for use as molluscicidal agents.

The need for an adequate molluscicide is so great, and the search so extensive, that man has gambled with the ecological balance of some geographical areas by introducing foreign organisms which attack and kill the intermediary snail host of schistosomiasis. Berg (1971) has described attempts of Hawaiian officials to introduce a Central American fly, Sepedon macropus, into snail breeding sites in Hawaii. The larva of this fly is predatory and feeds on the snail host of $\underline{S}$ mansoni. Kornicker (1972) has presented information that the ostracoid, $\underline{\text {. kawati, is }}$ an effective predator on the young of $\underline{B}$. glabratus and that the rate of predation increases dramatically with an increase in the number of ostracoids. Kornicker has postulated that these ostracoids would prove to be an effective biological control against the intermediary snail vectors of schistosomiasis.

While both chemical and biological controls are being investigated, the ultimate effect of these controls is still unknown. Biological control is extremely dangerous because man still does not know how to handle the delicate ecological balances of nature. Chemical control is also dangerous. Very little is known about the long term effects of molluscicides on man and animals.

Brown et al. (1967) studied the mammalian and avian toxicities of technical N-tritylmorpholine. He found that N-tritylmorpholine was non-toxic to rats, mice, sheep, 
chickens, and ducks and concluded that the use of this molluscicide would not constitute a hazard to the consumer or to domestic and wild animals. No studies have been conducted, however, on the teratogenic and carcinogenic effects of this agent. Until such data has been obtained, the practical employment of such a molluscicide must be considered unsafe.

B. THE MODE OF ACTIVITY OF MOLLUSCICIDAL AGENTS

Most molluscicides exhibit a mode of action characterized by either interference with the osmoregulatory system of the snail or interference with enzyme systems which are dependent on sulfhydryl groups (de Villiers, 1963). de Villiers showed that, on the basis of sulfhydryl reactivity, the phenacyl halides were potent molluscicidal agents. Zsolnai (1970) investigated the molluscicidal action of a number of compounds which react with thiol groups and are sulfhydryl enzyme inhibitors. The majority of these compounds proved to be effective molluscicides, and a few exhibited the same degree of efficacy as the best of the molluscicides used today. Ishak et a1. (1970) has shown that niclosamide (bayluscide) and sodiun pentachlorophenate inhibited intermediary metabolism of the snail B. alexandrina. Nabih and Metri (1971) have presented evidence that the widely used molluscicide, pentachlorophenol, is biologically oxidized by the snail, through the catalytic effect of peroxidase, to yield $2,2^{\prime}, 3,3^{\prime}, 5,5^{\prime}$, 6,6'-octachlorobiphenyl quinone which possesses potent molluscicidal activity. 
C. THE ROLE OF SULFHYDRYL GROUPS IN BIOLOGICAL PROCESSES

Many enzymes are simple proteins and need no additional factors to exhibit full activity. Some of these proteins, however, exist as inactive proenzymes or zymogens. To transform the zymogen to an active enzyme an inhibitory or blocking peptide must be removed. Another type of zymogen activation depends on maintaining the integrity of reduced sulfhydryl groups in the enzyme. These sulfhydryl groups may maintain or perhaps constitute part of the active center of the enzyme. Oxidation of two sulfhydryl groups to the disulfide (-S-S-) form inactivates the enzyme. Thus the proteolytic enzyme papain is inert after exposure to oxygen; when a suitable reductant is added to convert the disulfide form to the sulfhydryl form, papain becomes fully activated. Similar observations have been made with a large number of enzymes including triosephosphate dehydrogenase and pyruvic carboxylase (Conn and Stumpf, 1967).

The involvement of one or more sulfhydryl groups in the energy transfer steps of the oxidative phosphorylation system has been demonstrated by several workers. Lam (1968) has demonstrated the presence of sulfhydryl groups in a soluble factor involved in the stimulation of the ATP-driven NAD-reduction by succinate in selected mitochondrial ammonia particles and stated that the involvement of sulfhydryl groups is suggestive of a catalytic role. Ramakrishna Kurup and Sanadi (1968) have 
found that the organic mercurials cause a $90 \%$ inhibition in: a) the reduction of $\mathrm{NAD}$ by succinate coupled to the aerobic. oxidation of ascorbate-N,N, $N^{\prime}, N^{\prime}$-tetramethyl-p-phenylenedi- . amine and b) the nicotinamide nucleotide transhydrogenase reaction driven by the energy from the oxidation of ascor-

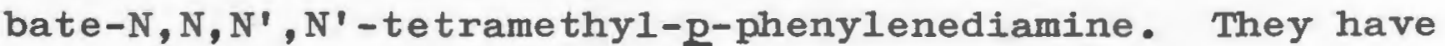
concluded that the mercurials act by inhibiting the generation of nonphosphorylated high-energy intermediates and point to the involvement of sulfhydryl groups in the early reactions of oxidative phosphorylation. Haugaard et al. (1969) have shown that a reactive site involving a SH group is intimately involved in either the entrance of inorganic phosphate into the mitochondria or the formation of a phosphorylated intermediate essential for oxidative phosphorylation and ion transport.

Sulfhydryl groups have been shown to be required for membrane integrity and function. Knauf and Rothstein (1971) have shown that the organic mercurial para-chloromercuriphenylsulfonic acid (PCMBS) inhibits the active transport of ions in red blood cell membranes and suggested that the mechanism of action is related to the effect of the mercurial on the sulfhydryl groups of the $\mathrm{Na}^{+}-\mathbf{k}$ activated ATPase system. Hegener (1968) has presented evidence that a number of mercurials cause an increase in lysosomal membrane permeability by reacting with membrane sulfhydryl groups. Watkins et al. (1970) have shown that alloxan and other sulfhydryl reagents cause an increase in the permeability of toadfish beta islet 
cells to mannitol and have suggested that they may damage cell membranes by combining with sulfhydryl groups essential for their integrity. "Solberg and Forte (1971) have shown that sulfhydryl reagents decrease hydrogen ion secretion in the isolated frog gastric mucosa.

Mackworth (1946) has shown that the lachrymatory effect of certain war gases is due to the reaction of these compounds with thiol enzymes such as succinic dehydrogenase, choline dehydrogenase, yeast alcohol dehydrogenase, papain, pyruvic oxidase, triosephosphate dehydrogenase, xanthine oxidase, and carboxylase. Chang et al. (1970) have confirmed the evidence that various sulfhydryl reagents cause conduction blockade of the motor axon, depolarization of the muscle membrane, sustained contraction, and depression and prolongation of the muscle action potential in the rat phrenic nerve-diaphragm preparation. These results point toward an active role for sulfhydryl groups in neuronal pathways.

Landon and Forte (1971) have reviewed evidence indicating that a membrane bound $\mathrm{Na}^{+}-\mathrm{K}_{\mathrm{K}}$ ATPase system is associated with the transport process of $\mathrm{Na}^{+}$and $\mathbf{K}$ in mammalian cells. It has been postulated that this system participates in renal tubular reabsorption of $\mathrm{Na}^{+}$. Lehninger (1971) has cited evidence demonstrating that the ATPase activity of myosin is dependent on the integrity of specific sulfhydryl groups. Organic mercurial diuretics have been 
shown to inhibit sodium-potassium dependent ATPase activity whereas non-diuretic mercurials have been shown to have no effect on $\mathrm{Na}^{+}-\mathrm{K}^{+}$dependent ATPase activity (Landon and Forte, 1971). Because the kidney accumulates the highest tissue levels of mercury (mercury is a sulfhydryl reagent with a high equilibrium affinity constant for the reaction between the $S$ atom of a thio group and mercury) sulfhydryl groups are believed to play an important role in normal renal function (clarkson, 1972).

D. BIOCHEMICAI, CHARACTERISTICS OF GASTROPODS

The class Gastropoda, containing the orders Pulmonata and Prosobranchiata, embraces all the intermediate hosts of Schistosoma. All snail hosts of $\underline{S}$ mansoni belong to the family Planorbidae of the order Pulmonata (Jordan and Webbe, 1969).

Evidence has accumulated indicating that pulmonates excrete uric acid via an organ which functions in a manner similar to the human kidney (Picken, 1937; Muller, 1963). Potts $(1967,1968)$ has stated that the gastropods synthesize uric acid via a biochemical pathway similar to that of mammals.

Muller (1963) has demonstrated that alkaline and acid phosphatases are widely distributed in the Pulmonate A. glabratus. Both classes of enzymes were found in the kidney and albumin gland. Wright et al. (1967) have reported similar data. Emerson (1967) has shown that the metabolism of the pulmonate $\underline{P}$. corneus is carbohydrate oriented.

Weinbach (1952) has demonstrated that cyanide 
depresses endogenous respiration in A. Elabratus and that methylene blue prevents this cyanide related depression. He suggested that the electron transport to molecular oxygen in minced snail tissue is via a cytochrome oxidase system. He also demonstrated that arsenate and p-chloromercuribenzoate inhibited respiration and suggested the existence of sulfhydryl dependent enzymes. Weinbach has also demonstrated that the addition of TCA intermediates to snail minces stimulated respiration. This data, plus the demonstration of the existence of the key enzymes cytochrome oxidase, succinic dehydrogenase, malic dehydrogenase, and fumarase, suggest that some mechanism similar to the TCA cycle is operating in the living snail, permitting in the normal manner, the efficient utilization of pyruvate. Coles $(1969 a, b)$ has shown that nine dehydrogenases, beta glucosidase, beta glucuronidase, peroxidase, and leucine amino peptidase exist in the pulmonates B. sudanica, $\underline{B}$. africanus, and $\underline{B}$. nastus, and has concluded that the concentration of malic dehydrogenase, isocitric dehydrogenase, and two enzymes of the pentose phosphate pathway are so high that both the TCA cycle and pentose phosphate pathway must be functioning in the snails tested.

\section{E. THE MECHANISM OF ACTION OF BETA-NITROSTYRENES}

Beta-nitrostyrene and its derivatives are known to be potent molluscicidal agents. Louis-Ferdinand (1970) has reported that the structure of the beta-nitrostyrenes is 
compatible with the hypothesis that the reactivity of these and other nitroolefins with protein functional groups is an important factor contributing to their toxicity. Polarization of the alpha-beta unsaturation by electron withdrawing groups would enhance the reactivity of the betanitro-styrenes towards protein hydroxyl, amino, and sulfhydryl groups. Previous work (Louis-Ferdinand, 1969) had shown that beta-nitrostyrene reacts with cysteine sulfhydryl groups in vitro in the absence of any interaction with amino acid hydroxyl or amino groups.

Louis-Ferdinand (1970) showed a correlation between the inhibition of oxygen uptake in A. Elabratus and the sulfhydryl reactivity of the molluscicidal beta-nitrostyrene series. He postulated that the molluscicidal activity of the beta-nitrostyrenes may be mediated through an interaction of these agents with sulfhydryl groups of susceptible biologic systems.

F. VINYL SULFONE: THE HISTORY OF AND RELATIONSHIP BETWEEN VINYL SULFONE AND BETA-NITROSTYRENE

Vinyl sulfone has been shown to be a very reactive substance and reacts readily with amino, hydroxyl, and sulfhydryl groups of various compounds, the hydrogen atom adding to the alpha carbon and the rest of the molecule to the beta carbon. Reaction with a mercapto group is particularly rapid, and, when vinyl sulfone reacts with a substance such as cysteine, which contains both mercapto and amino groups, combination occurs predominant1y with the 
former. This reactivity extends to those compounds, like phenyl vinyl sulfone, that only contain one vinyl group (Ford-Moore et a1. 1950).

Interest first developed in vinyl sulfone when it was discovered that vinyl sulfone was a possible metabolite of bis (beta-chloroethy1) sulfide or mustard gas. Mustard gas was the chief chemical agent employed in the first World War. Numerous studies on the toxicological action of mustard gas were conducted from 1917 to 1939. It was known that, in sufficient doses, vinyl sulfone produced systemic intoxication which culminated in death. The mechanism of this systemic intoxication, however, was obscure. Researchers hoped that, by studying related compounds, the action of mustard gas and other beta-chloroethyl vesicants could be correlated with chemical structure and reactivity.

Several theories have been proposed to account for the vesicant and toxic properties of mustard gas. One such theory postulated that mustard gas was oxidized to $2,2^{\prime}$-dichlorodiethyl sulfone and that this sulfone was the actual toxic agent (Ford-Moore et al. 1949). Ford-Moore then demonstrated that the intermediate $2,2^{\prime}$-dichlorodiethyl sulfone could undergo hydrolysis to yield a very active compound called divinyl sulfone or vinyl sulfone. Buckley et a1. (1947) aided the development of this theory by providing a convenient method for the synthesis of vinyl sulfone.

Anslow et al. (1947) studied the toxicity of various 
compounds related to mustard gas. They investigated the toxicity of vinyl sulfone on the basis of the theory that mustard gas may be oxidized to mustard sulfone or vinyl sulfone. Toxicity was studied in mice and rats which had been administered the compounds either cutaneously or intravenously. An intravenous $L D_{50}$ of $11 \mathrm{mg} / \mathrm{kg}$ for mice and $12 \mathrm{mg} / \mathrm{kg}$ for rats was reported. High doses were reported to produce pulmonary edema and death in rats within twentyfour hours. Marked parasympathomimetic activity terminating in clonic convulsions and death were reported on intravenous administration of vinyl sulfone to rabbits. Cordier and Cordier (1950) studied the effects of oxidation products of mustard gas on the cardiovascular system in order to determine whether the atropine like effects and toxicity of mustard gas were due to the intact molecule or a breakdown product of mustard gas. Vinyl sulfone produced transient hypertension followed by prolonged hypotension (sometimes terminating in death) and had no effect on salivary secretions. It was therefore determined that the effects of mustard gas were due to the intact molecule.

Ford-Moore et al. (1949) have cited evidence which they believe indicates that the reaction between sulfhydryl groufis and compounds such as vinyl sulfone may be reversible under biological conditions. The basis of this belief is that the thioether linkage of the reaction between vinyl sulfone and cysteine can be split, at slightly alkaline pH, with silver salts. 
The sulfhydryl reactivity of vinyl sulfone is we11 documented (Ford-Moore et al. 1950; Buckley et al. 1947;. Ford-Moore et al. 1949; and Yuki et al. 1966), and its pharmacological and toxicological properties have been linked with this reactivity. Grant et al. (1946) studied the effect of mustard gas and vinyl sulfone on the activity of urease, a sulfhydryl dependent enzyme. Vinyl sulfone was found to inactivate the enzyme between $\mathrm{pH} 6$ and $\mathrm{pH} 8$. and its effect was linked to dissociation characteristics and reactivity of the sulfhydryl groups with vinyl sulfone at those $\mathrm{pH}^{\prime} \mathrm{s}$.

Watkins et al. (1952) found that hemolytic complement is rapidly inactivated by small amounts of vinyl sulfone or S-mustard. Thiosulfite was found to protect against both substances. Inactivation was thought to be the result of reaction between vinyl sulfone and the sulfhydryl groups of complement.

Peters and Wakelin (1949) studied the effects of mustard gas, dichlorodiethyl sulfone, and vinyl sulfone on the pyruvic oxidase system in pigeon brain tissue. The system was studied because it was a known sulfhydryl dependent enzyme system, and their initial hypothesis was that vesication was due to damage of sulfhydryl dependent enzymes.

\section{Dichlorodiethyl sulfone and vinyl sulfone were} found to inhibit the pyruvic oxidase system at concentrations of $10^{-4} \mathrm{M}$. On a molar basis, vinyl sulfone was found 
to be the more toxic. Vinyl sulfone had no effect on cytochrome oxidase while mustard gas, dichlorodiethyl sulfone and vinyl sulfone exhibited low inhibitory effects on malic, latic, and succinic dehydrogenase. No effect on amino acid oxidase was observed.

Some correlation between the toxicity of non-arsenical vesicants to the pyruvic oxidase system and vesicant potency was observed. They concluded that, like the arsenicals, dichlorodiethyl sulfone and vinyl sulfone combine with sulfhydryl groups of enzymes. This was supported by the toxicity values and earlier work which demonstrated decreased sulfhydryl reactions of skin slices when treated with vinyl sulfone or dichlorodiethyl sulfone.

Nambara (1954) observed that vinyl sulfone is an effective bacteriostatic agent and is active against $\underline{M}$.

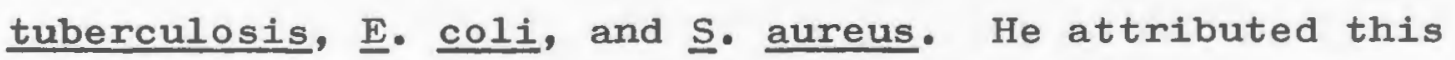
action to the reactivity of vinyl sulfone with hydroxyl, amino, and sulfhydryl groups. Baker et al. (1966) have shown that vinyl sulfone is an effective bactericidal and fungicidal agent at concentrations of 5 to 50 parts per million.

Aechenegg and Emerson (1960) have shown that vinyl sulfone is an effective nematocide against Panagrellus sp. and Meloidgyne sp..

Yuki et al. (1966) studied seventy-one sulfhydryl reagents and classified them according to their ability to react with methyl-N-acetylcysteine and inactivate adenovirus 
type 5. He found that vinyl sulfone exhibited a high degree of sulfhydryl reactivity but had no effect on the activity of the adenovirus.

In all cases the toxicity of vinyl sulfone has been linked to its sulfhydryl reactivity. Vinyl sulfone and its derivatives exhibit molluscicidal activity (Bond, 1971) and possess an electron withdrawing $\mathrm{SO}_{2}$ group with an alpha-beta unsaturation directly adjacent to it. The structure then of vinyl sulfone is similar to that of the beta-nitrostyrenes. The fact that both classes of compounds are molluscicidal and both contain structural portions which are very similar leads to the hypothesis that vinyl sulfone may exert biological activity via a mechanism similar to that of the beta-nitrostyrenes.

This study has been designed to determine whether the vinyl sulfones exert any effect on respiration in $A$. glabratus or in rats and whether their toxicities can be correlated with sulfhydryl reactivity and decreased respiration. 


\section{EXPERIMENTAL}

\section{A. REAGENTS}

Reagents used were analytical grade or equivalent. Co-factors, substrates, and amino acids were obtained from Calbiochem (Los Angeles, California), Sigma (St. Louis, Mo.), or Nutritional Biochemicals (Cleveland, Ohio). Malic Cehydrogenase was obtained from Worthington of Freehold, New Jersey. Vinyl sulfone, beta-nitrostyrene, and 5,5'-dithiobis(2-nitrobenzoic acid) was obtained from Aldrich (Milwaukee, Wisconsin).

CliniTest reagent tablets were obtained from Ames (Elkhart, Indiana) and the reagents for the determination of blood urea nitrogen (B.U.N.-tel) were supplied by the diagnostic division of Pfizer (New York, New York).

Derivatives of vinyl sulfone were prepared by the Medicinal Chemistry Department of the College of Pharmacy, University of Rhode Island.

\section{B. ANIMALS}

Laboratory reared Australorbis glabratus were porvided by Dr. H. Bond of the Medicinal Chemistry Department, College of Pharmacy, University of Rhode Island. Once obtained, the snails were maintained on an ad libitum diet of romaine lettuce in an aquarium containing distilled water. Marble chips were placed in the aquarium as a supply of calcium. 
Male and female albino rats, obtained from Charles River Breeding Laboratories (Wilmington, Mass.), weighing 100 to 500 grams were used. The animals were housed in quarters maintained at 21 to $23^{\circ} \mathrm{C}$ with room 1 ights on a1ternating twelve-hour light-dark cycles. Commercial laboratory chow and water were allowed ad libitum.

\section{ANALYTICAL PROCEDURES}

1. DETERMTNATION OF SULFHYDRY, REACTIVITY

Sulfhydryl reactivity was determined by observing the total absorbance change produced by the colorforming reaction between cysteine and $5,5^{\prime}$ dithiobis $(2-$ nitrobenzoic acid) (DTNB) in the presence and absence of the sulfhydryl reactive agent (Louis-Ferdinand and Fuller, 1969). Ethanolic solutions of the vinyl sulfones were added to the test medium (containing $7 \mathrm{ml}$ of cysteine $(0.256 \mathrm{mM}), 10 \mathrm{mI}$ ethylenediaminetetraacetic acid $(0.5 \mathrm{M})$ adjusted to $\mathrm{pH} 7.3$ with potassium hydroxide, $5 \mathrm{ml}$ deLonized water, and $6 \mathrm{ml}$ of phosphate buffer (0.1M) pH 7.3) one minute prior to a twenty-minute incubation period at $30^{\circ} \mathrm{C}$ with constant shaking in a Precision-Dubnoff shaker bath and incubator. Immediately after the incubation period, 50 microliters of DTNB $(2 \mathrm{mg} / \mathrm{ml}$ prepared fresh daily in $0.1 \mathrm{M}$ phosphate buffer $\mathrm{pH} 7.3$ ) were pipetted into a Beckman sample cuvette (containing two $\mathrm{ml}$ of the reaction medium) to initiate color development. The cuvette 
412 nanometers in a spectrophotometer having the sample chamber incubated at $30^{\circ} \mathrm{C}$. One ethanol blank was run for each concentration tested.

\section{DETERMINATION OF MALIC DEHYDROGENASE ACTIVITY}

The activity of malic dehydrogenase (MDH) was determined by observing the linear absorbance change produced by the oxidation of $\mathrm{NADH}$ in the presence of the enzyme and oxalacetate (Ochoa, 1955). The effect of vinyl sulfone on the activity of $\mathrm{MDH}$ was determined by comparing the rate of oxidation of NADH with and without added vinyl sulfone. Acetone solutions of vinyl sulfone were added to the reaction medium (containing delonized water, $0.3 \mathrm{ml}$ of $0.25 \mathrm{M}$ glycylglycine buffex $\mathrm{pH} 7.4,0.1 \mathrm{ml}$ of $3 \times 10^{-3} \mathrm{M} \mathrm{NADH}$, and 1.08 units of porcine $\mathrm{MDH}$ in a final volume of three m1) and incubated at room temperature for one hour. Immediately after the incubation period, the reaction medium was transferred to a Beckman sample cuvette and $0.1 \mathrm{ml}$ of $7.6 \times 10^{-3} \mathrm{M}$ oxalacetate added. The cuvette was inverted once and the rate of oxidation of $\mathrm{NADH}$ followed at 340 nanometers in a Beckman DB-G spectrophotometer connected to an accessory $10^{\prime \prime}$ linear $\log$ recorder. Control samples were run in the presence of acetone.

3. DETERMINATION OF IN VITRO ENDOGENOUS RESPIRATION IN AUSTRALORBIS GLABRATUS

Endogenous respiration was measured manometriçal1y. Whole snails were carefully removed from their shells 
and each was placed into a Warburg flask containing three $\mathrm{ml}$ of $0.1 \mathrm{M}$ phosphate buffer pH 7.4 (Weinbach, 1952). Ethanolic solutions of vinyl sulfone were added to the sample flasks while an equal volume of absolute ethanol was added to control flasks. A strip of filter paper and $0.2 \mathrm{ml}$ of a $20 \%$ solution of potassium hydroxide were then placed into the center well of each flask. The flasks were placed on their respective manometers and allowed to equilibrate in a $100 \%$ oxygen atmosphere with constant shaking at $30^{\circ} \mathrm{C}$ for ten minutes.

Immediately after the equilibration, oxygen uptake was monitored every ten minutes for one hour. Following the measurement of oxygen uptake, the whole snail was removed, placed into a pre-weighed aluminum dish, and dried at 90 to $100^{\circ} \mathrm{C}$ for twenty-four hours. The dry weight of the tissue was calculated and the endogenous respiration expressed as the $\mathrm{QO}_{2}$ (microliters oxygen/mg dry tissue/hour).

4. DETERMINATION OF AN APPROXIMATE LD 50 FOR VINYL SULFONE

Four groups of five female albino rats, weighing 125-150 grams, were injected, intraperitoneally, with 0.5 , $1.5,2.5$, or $3.5 \mathrm{mg} / \mathrm{kg}$ vinyl sulfone. The vehicle of injection was $5 \%$ ethanol. Groups were observed and deaths noted for fourteen days.

\section{PROTECTION STUDIES WITH CYSTEINE}

Groups of five male or five female albino rats, 
weighing 150-300 grams, were injected, intraperitonea11y or subcutaneously, with $250 \mathrm{mg} / \mathrm{kg}$ cysteine hydrochloride adjusted to $\mathrm{pH} 7.3$ with sodium hydroxide.

Animals receiving cysteine intraperitoneally were administered vinyl sulfone $(6 \mathrm{mg} / \mathrm{kg}$ ) intraperitoneally fifteen minutes later. Animals receiving cysteine subcutaneously were administered vinyl sulfone (6 mg/kg) intraperitoneally forty-five minutes after the administration of cysteine. Groups were observed and deaths noted for fourteen days.

\section{DETERMINATION OF IN VITRO ENDOGENOUS RESPIRA-} TION IN RAT TISSUE SLICES

Endogenous respiration was measured manometrically. Female rats, weighing 125-150 grams, were sacrificed and their brains or livers were removed and placed on ice. Tissue slices were then prepared freehand according to the method of Deutsch (1936) and placed into Warburg flasks containing three $\mathrm{ml}$ of Krebs-Ringer phosphate solution. Ethanolic solutions of vinyl sulfone were added to the sample flask while an equal volume of absolute ethanol was added to the control flasks. A strip of filter paper and $0.2 \mathrm{ml}$ of a $20 \%$ solution of potassium hydroxide were placed into the center well of each flask. The flasks were then placed on their respective manometers and allowed to equilibrate in a $100 \%$ oxygen atmosphere with constant shaking at $37^{\circ} \mathrm{C}$ for ten minutes. 
Immediately after the equilibration, oxygen uptake was monitored every ten minutes for one hour. The tissue slices were then removed from the flasks, placed into preweighed aluminum dishes, and dried at $90-100^{\circ} \mathrm{C}$ for twentyfour hours. The dry weight of the tissue was calculated and the endogenous respiration expressed as the $\mathrm{QO}_{2}$.

7. DETERMINATION OF ENDOGENOUS RESPIRATION IN BRAIN SLICES OF FEMALE RATS TREATED IN VIVO WITH VINYL SULFONE

Fndogenous respiration was measured manometrically. Female rats, weighing 125-150 grams, were injected, intraperitoneal1y, with vinyl sulfone $(20 \mathrm{mg} / \mathrm{kg})$ or $5 \%$ ethanol ( $1 \mathrm{ml} / \mathrm{kg}$ ). One-half hour later the animals were sacrificed and the brains removed and placed on ice. Brain slices were prepared freehand, potassium hydroxide added to the center we11, and the flasks placed on their respective manometer's. Oxygen uptake was then monitored in the manner described in Analytical Procedures \#6.

\section{DETERMINATION OF IN VITRO PYRUVATE METABOLISM IN LIVER AND BRAIN HOMOGENATES OF MALE RATS} Pyruvate metabolism was measured manometrically. Male rats, weighing 300-500 grams, were sacrificed and their brains or livers removed and placed on ice. The organs were then minced and homogenized in ice-cold $1.15 \%$ KC1. Fifty milligrams (0.5 $\mathrm{ml}$ of a $100 \mathrm{mg} / \mathrm{ml}$.homogenate) of tissue were placed into Warburg flasks containing (in 
a final volume of $4.1 \mathrm{ml}) 6$ micromoles of potassium fumarate, 6 micromoles of sodium pyruvate, 12 micromoles of magnesium chloride, 3 micromoles of adenosine triphosphate, 585 micromoles of sucrose, and $0.5 \mathrm{ml}$ of $0.1 \mathrm{M}$ phosphate buffer pH $7 \cdot 3$.

Ethanolic solutions of vinyl sulfone were added to sample flasks while an equal volume of ethanol was added to the control flasks. A strip of filter paper and $0.2 \mathrm{ml}$ of a $20 \%$ solution of potassium hydroxide were placed into the center well of each flask. The flasks were then placed on their respective manometers and allowed to equilibrate in a $100 \%$ oxygen atmosphere at $37^{\circ} \mathrm{C}$ for five minutes. Five micromoles $(0.5 \mathrm{ml})$ of $\mathrm{NAD}$ were then tipped into the flasks from their sidearms and the flasks allowed to equilibrate, with constant shaking, for five minutes.

Immediately after the equilibration period, oxygen uptake was monitored every five minutes for thirty minutes. Pyruvate metabolism was expressed as microliters of oxygen taken up per milligram wet tissue per thirty minutes.

\section{DETERMINATION OF PYRUVATE METABOLISM IN LIVER,} KIDNEY, AND BRAIN HOMOGENATES OF MALE RATS TREATED IN VIVO WITH VINYL SULFONE

Pyruvate metabolism was measured manometrically. Male rats, weighing 250-500 grams, were injected, intraperitoneally, with 10 or $20 \mathrm{mg} / \mathrm{kg}$ vinyl sulfone. After two hours the animals were sacrificed and the liver, kidney 
or brain removed and placed on ice. The organ was then minced and homogenized in 1.15\% ice-cold KCl. Fifty milligrams of tissue were then placed into Warburg flasks (containing the same medium as described in Analytical Procedures \#8), potassium hydroxide added to the center we11, and the flasks placed on their respective manometers. Oxygen uptake was then monitored in the manner described in Analytical Procedures \#8.

\section{DETERMINATION OF HEMATOCRIT LEVELS IN MALE RATS} Male rats, weighing 200-500 grams, were pretreated with vinyl sulfone (10 mg/kg.or $2 \mathrm{mg} / \mathrm{kg}$ ) or $0.5 \%$ carboxymethylcellulose (in the case of the $10 \mathrm{mg}$ dose) or $5 \%$ ethanol (in the case of the $2 \mathrm{mg}$ dose) ( $1 \mathrm{ml} / \mathrm{kg}$ ). Rats treated with $10 \mathrm{mg} / \mathrm{kg}$ vinyl sulfone were bled, via tail slash, 90 minutes after treatment. Rats receiving $2 \mathrm{mg} / \mathrm{kg}$ vinyl sulfone were part of the blood chemistry and urine analysis study and were bled 72 hours after treatment. Blood was collected in hèparinized capillary tubes and placed into a Adams Micro Hematocrit centrifuge. The capillary tubes were centrigued for five minutes and the ratio of packed cells to volume determined using a centimeter ruler.

\section{BLOOD CHEMISTRIES AND URINE ANALYSES}

a. DETERMINATION OF SGOT AND SGPT LEVELS SGOT and SGPT levels were determined accord- 
ing to the method of Reitman and Frankel (1957). Female rats, weighing 125-150 grams, were treated intraperitoneally with either vinyl sulfone $(2 \mathrm{mg} / \mathrm{kg})$ or $5 \%$ ethanol. ( $1 \mathrm{ml} / \mathrm{kg})$ and placed in individual metabolism cages with free access to food and water. Three days after treatment the animals. were bled, via tail slash, and the blood collected.

One $\mathrm{m} 1$ of the appropriate substrate was then placed into a test tube incubated at $37^{\circ} \mathrm{C}$. Two-tenths $\mathrm{ml}$ of serum were added and the tube allowed to incubate for thirty minutes. Samples used for the determination of SGoT were incubated for sixty minutes.

Following the incubation period, one ml of 2,4dinitrophenylhydrazine was added to each tube. The samples were allowed to stand at room temperature for twenty minutes and then ten $\mathrm{ml}$ of $0.4 \mathrm{~N}$ sodium hydroxide were added to each tube. Reagent and tissue blanks were run for each analysis in the same manner. After thirty minutes the absorbance of each sample was determined spectrophotometrical$1 y$ at 520 nanometers against a water blank.

A standard curve was run simultaneously with the treated and control samples and SGOT and SGPT levels were calculated from the graph of the standard curve.

b. DETERMINATION OF BLOOD UREA NITROGEN

Blood urea nitrogen was determined using the diacetyl monoxime method of Rosenthal (1955). The system utilized was the B.U.N. te ${ }^{R}$ kit of Pfizer Diagnostics Division. Male rats, weighing 200-300 grams, were injected 
intraperitoneally with either vinyl sulfone $(2 \mathrm{mg} / \mathrm{kg}$ ) or $5 \%$ ethanol $(1 \mathrm{ml} / \mathrm{kg})$ and placed in individual metabolism cages with free access to food and water. Three days after treatment the animals were bled, via tail slash, and the blood collected.

Twenty microliters of serum were then placed into tubes containing three $\mathrm{ml}$ of reagent A (ferric chloride, phosphoric acid, and sulfuric acid) and two ml of reagent B (thiosemicarbizide and diacetylmonoxime) and boiled for ten minutes. Immediately after bolling, the tubes were cooled in cold water for five minutes and the absorbance of the samples determined spectrophotometrically at 480 nanometers against a reagent blank.

A standard curve was run simultaneously with the treated and control samples and the blood urea nitrogen levels calculated from the graph of the standard curve.

$$
\text { c. DETERMINATION OF URINARY VOLUME, } \mathrm{pH} \text {, SUGAR }
$$

\section{AND PROTEIN}

Urine samples were collected from the male rats treated in part $b$ of this section. Samples were collected over a twenty-four hour period starting fortyeight hours after treatment with vinyl sulfone.

Urinary volume was measured to the nearest milliter with a graduated cylinder and urinary $\mathrm{pH}$ was determined using Ames $\mathrm{pH}$ paper.

Urinary sugar was determined by means of Ames cliniTest tablets. 
Urinary albumin (protein) was determined using the sulfosalicylic acid method described in the Manual of Clinical Laboratory Techniques. (Faulkner and King, 1970).

\section{STATISTICAL METHODS}

The two-tailed Student's "t" test for independent means, calculated on an Olivetti Underwood Programma 101 desk computer, was used to test for differences between means. The formula employed was:

$$
t=\frac{\bar{x}_{1}-\bar{x}_{2}}{\sqrt{\frac{1}{n_{1}}+\frac{1}{n_{2}}}}
$$

$$
\text { where } s^{2}=\frac{\left(n_{1}-1\right) s_{1}^{2}+\left(n_{2}-1\right) s_{2}^{2}}{n_{1}+n_{2}-2}
$$

$$
\begin{aligned}
& \mathbf{n}_{1}=\text { Control sample size } \\
& \mathbf{n}_{2}=\text { Treated sample size } \\
& \mathbf{s}_{1}^{2}=\text { Control sample variance } \\
& \mathbf{s}_{2}^{2}=\text { Treated sample variance } \\
& \bar{x}_{1}=\text { Control sample mean } \\
& \bar{x}_{2}=\text { Treated sample mean }
\end{aligned}
$$

The degrees of freedom were taken as $n_{1}+n_{2}-2$. The level of significance ( $p$ ) was determined by comparison of "t" with values from standard tables. All calculated " $t$ " values were tested at the 0.05 level for acceptance or rejection of the null hypothesis. 
Determination of the correlation coefficient between the toxicity and sulfhydryl reactivity of the derivatives of vinyl sulfone was calculated by the formula (Dixon and Massey, 1951) as follows:

$$
\begin{aligned}
& \text { Correlation Coefficient }=p=\frac{E\left(X-u_{x}\right)\left(Y-u_{y}\right)}{S_{x} S_{y}} \\
& \text { Where } r \text { is the estimator of } p \\
& \text { and } r=\frac{\Sigma\left(x_{i}-\bar{X}\right)\left(Y_{i}-\bar{Y}\right)}{\sqrt{\Sigma\left(X_{i}-\bar{X}\right)^{2} \Sigma\left(y_{i}-\bar{Y}\right)^{2}}}
\end{aligned}
$$

and

$\mathbf{X}_{i}=$ Independent measurements

$Y_{i}=$ Dependent measurements

$\overline{\mathrm{X}}=$ Mean of the independent measurements

$\bar{Y}=$ Mean of the dependent measurements

Regression curves were determined according to the formula of Dixon and Massey (1951) using an olivetti Underwood desk model computer. The formula used was as follows :

$$
\begin{aligned}
& Y_{i}=a+b\left(X_{i}\right) \\
\text { Where } b=\text { slope }= & \frac{\sum X_{i} Y_{i}-n \overline{X Y}}{\sum X_{i}^{2}-n \bar{X}^{2}}
\end{aligned}
$$


And $a=Y$ intercept $=\bar{Y}-b \bar{X}$

$$
\begin{aligned}
& \mathbf{X}_{\mathbf{i}}=\text { Independent measurement } \\
& \mathbf{Y}_{\mathbf{i}}=\text { Dependent measurement } \\
& \overline{\mathbf{X}}=\text { Mean of the independent measurements } \\
& \overline{\mathbf{Y}}=\text { Mean of the dependent measurements } \\
& \mathbf{n}=\text { Number of paired observations }
\end{aligned}
$$

The ' $t$ ' statistic was used to test the hypothesis that the correlation coefficient $p$ was equal to zero. The equation used was as follows:

$$
\begin{aligned}
& \qquad t=r \sqrt{\frac{n-2}{1-r^{2}}} \\
& \text { and } \\
& r=\text { Correlation coefficient estimator } \\
& n=\text { Number of pairs of values compared } \\
& t=\text { ' } t \text { ' statistic } \\
& \text { The calculated ' } t \text { ' statistic was then compared with } \\
& \text { critical values for the 't' distribution. Hypotheses of } \\
& \text { equality between } p \text { and zero were rejected if the calculated } \\
& \text { statistic fell outside of the bounds of the critical values }
\end{aligned}
$$
$(\mathrm{P}<0.05)$ (Dixon and Massey, 1951). 
IV. RESULTS

\section{A. SULFHYDRYL REACTIVITY}

The reaction between $5,5^{\prime}$-dithiobis(2-nitrobenzoic acid) (DTNB) and a compound containing a sulfhydryl group is presented in Figure 1. The anion yielded in the reaction is yellow and the intensity of the yellow color can be used to determine the extent of reaction between DTNB and the sulfhydryl compound. Table 1 represents the effect of vinyl sulfone and derivatives on the color-forming reaction between DTNB and cysteine. Vinyl sulfone inhibits the reaction $15 \%$ when present at a concentration of $3.7 \times 10^{-5} \mathrm{M}$ and, at a $1.4 \times 10^{-4} \mathrm{M}$ concentration, inhibits the reaction 44\%. Various derivatives inhibit the reaction to a lesser extent while diethyl sulfone exhibits very little inhibitory effects even when present at concentrations as high as $5 \times 10^{-4} \mathrm{M}$.

Figure 2 represents the reactivity of vinyl sulfone and derivatives with sulfhydryl groups of cysteine. Four micromoles of vinyl sulfone react with 0.78 micromoles of cysteine. Various derivatives react with cysteine to a lesser extent while diethyl sulfone exhibits negligible reactivity with cysteine.

The data in Table 2 represents the relationship between the sulfhydryl reactivity (expressed as the sum of 
the $y$ coordinates divided by the sum of the $x$ coordinates of the curves in Figure 2) and the molluscicidal potency of vinyl sulfone and derivatives. Vinyl sulfone exhibits the highest degree of sulfhydryl reactivity and molluscicidal potency. Various derivatives exhibit decreased sulfhydryl reactivity and molluscicidal potency while diethyl sulfone shows negligible sulfhydryl reactivity and molluscicidal potency.

Table 3 represents the relationship between sulfhydryl reactivity and molluscicidal potency of $\mathrm{N}$-tritylmorpholine and $\mathrm{N}$-triphenylacetyl morpholine. Both $\mathrm{N}$-tritylmorpholine and $\mathrm{N}$-triphenylacetyl morpholine exhibit a high degree of molluscicidal potency; however, neither compound shows any measurable sulfhydryl reactivity, and, therefore no correlation can be obtained between sulfhydryl reactivity and molluscicidal potency.

Figure 3 shows the color-forming reaction between cysteine and DTNB in the absence or the presence of vinyl sulfone or phenyl vinyl sulfone (URI \#744). The color formed by the cysteine-DTNB reaction is stable for at least sixty minutes while the color formed by the reaction of cysteine and DTNB in the presence of vinyl sulfone or phenyl vinyl sulfone starts to decay immediately. The addition of cysteine after sixty minutes produces an increase in absorbance in either one of the test situations containing cysteine, DTNB, and a sulfone. 
FIGURE 1

\section{(REACTION OF $5,5^{\prime}$-DITHIOBIS (2-NITROBENZOIC ACID) \\ WITH THIOL COMPOUND}
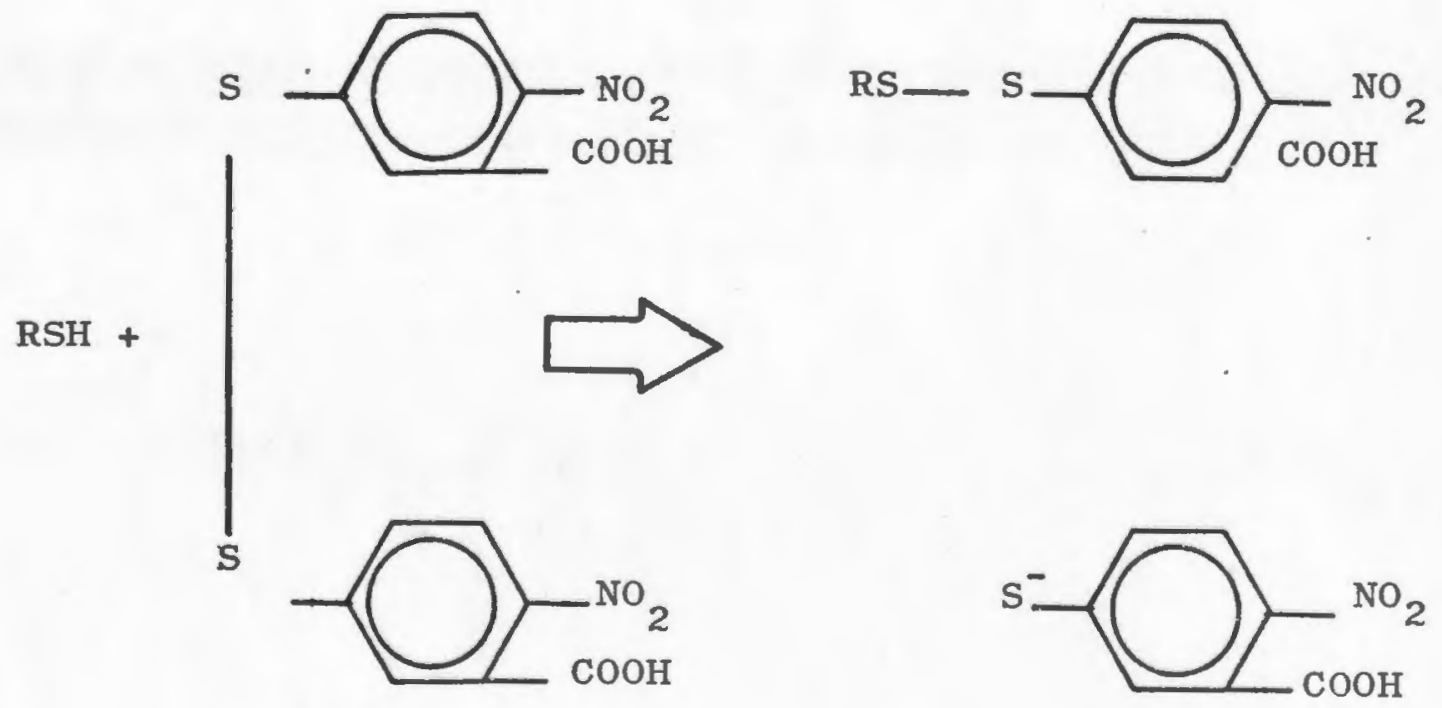
TABLE 1

EFFECT OF VINYL SULFONE AND DERIVATIVES ON THE COLOR-

FORMING REACTION BETWEEN DTNB ${ }^{a}$ AND SULFHYDRYL

GROUPS OF CYSTEINE

COMPOUND CONCENTRATION CONTROL

TREATED \% CHANGE

VINYL,

$$
3.7 \times 10^{-5} \mathrm{M}
$$

$0.76 \pm .02$

$0.65^{b} \pm .00$

$14^{\mathrm{c}}$

SULFONE

$1.4 \times 10^{-4} \mathrm{M}$

$0.71 \pm .00$

$0.40^{b} \pm .00$

$44^{c}$

URI \#793
$3.7 \times 10^{-5} \mathrm{M}$
$0.79 \pm .01$
$0.67^{\mathrm{b}} \pm .01$
$16^{\mathrm{c}}$
$1.7 \times 10^{-4} \mathrm{M}$
$0.72 \pm .00$
$0.35^{\mathrm{b}} \pm .02$
$51^{\mathrm{c}}$

URI $\# 744$

$7.2 \times 10^{-5} \mathrm{M}$

$0.76 \pm .00$

$0.70^{\mathrm{b}} \pm .00$

$9^{c}$

$3.2 \times 10^{-4} \mathrm{M}$

$0.66 \pm .00$

$0.45^{\mathrm{b}} \pm .00$

$33^{\mathrm{c}}$

URI \#760

$2.0 \times 10^{-4} \mathrm{M} \quad 0.74 \pm .00 \quad 0.64^{\mathrm{b}} \pm .01 \quad 15^{\mathrm{c}}$

$5.1 \times 10^{-4} \mathrm{M}$

$0.61 \pm .00$

$0.43^{b} \pm .01$

$29^{\mathrm{C}}$

\begin{tabular}{llllll}
\hline URI \#7 18 & $\begin{array}{l}3.7 \times 10^{-4} \mathrm{M} \\
8.2 \times 10^{-4} \mathrm{M}\end{array}$ & $\begin{array}{l}0.68 \pm .00 \\
0.46 \pm .00\end{array}$ & $\begin{array}{l}0.60^{\mathrm{b}} \pm .00 \\
0.35^{\mathrm{b}} \pm .00\end{array}$ & $\begin{array}{l}11^{\mathrm{c}} \\
23^{\mathrm{c}}\end{array}$ \\
\hline DIETHYL & $2.0 \times 10^{-4} \mathrm{M}$ & $0.62 \pm .00$ & $0.61^{\mathrm{b}} \pm .00$ & 1 \\
SULFONE & $5.1 \times 10^{-4} \mathrm{M}$ & $0.53 \pm .00$ & $0.52^{\mathrm{b}} \pm .00$ & 2 \\
\hline
\end{tabular}

a. 5,5'-dithiobis(2-nitrobenzoic acid).

b. Represents the mean and standard error of six determinations.

c. Statistically significant. P 0.05 . 


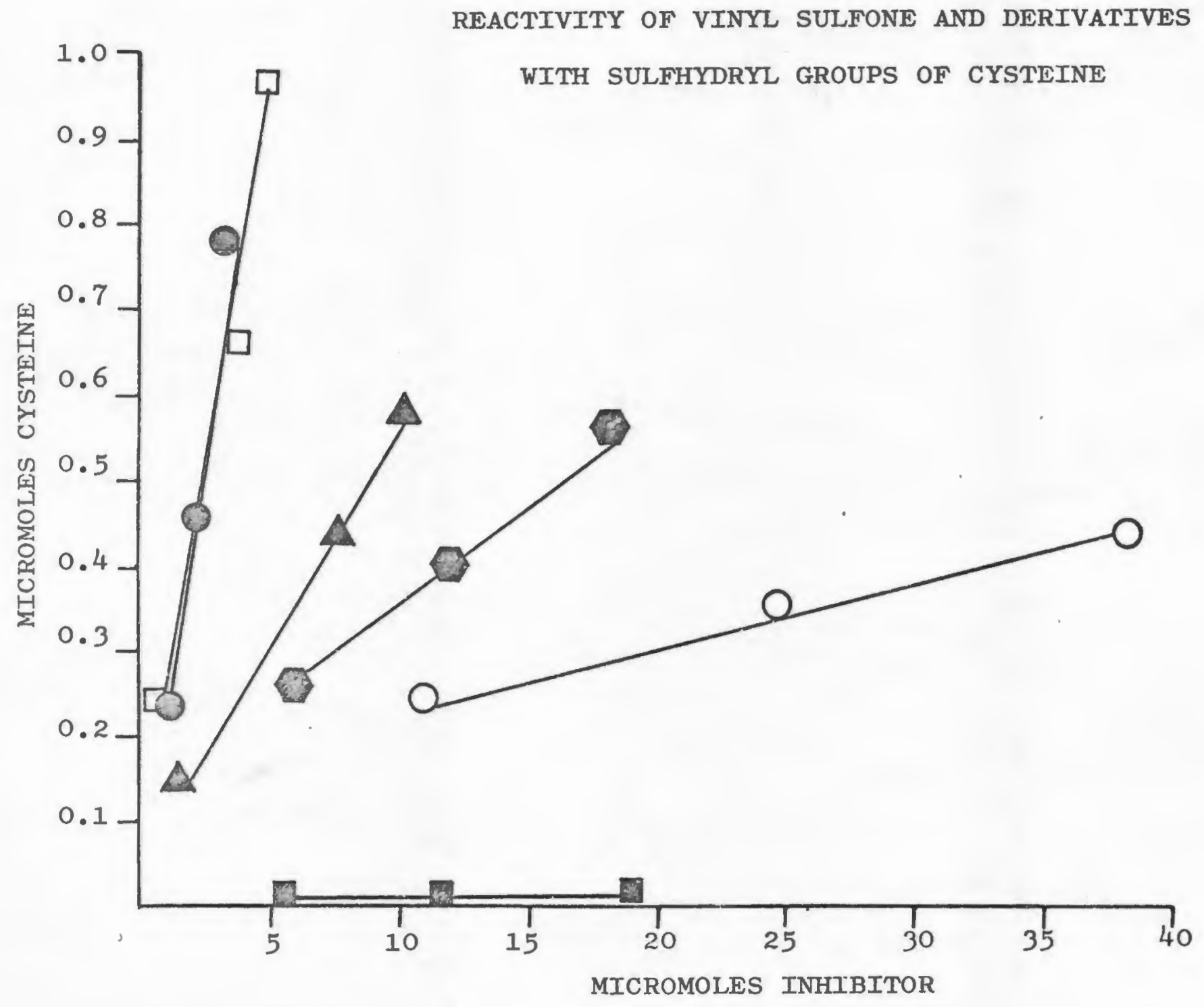

情

근 VINYL SULFONE $\square$ URI \#793

$\triangle$ URI \#744

URI \#760

URI \#718

(3) DES 
TABLE 2

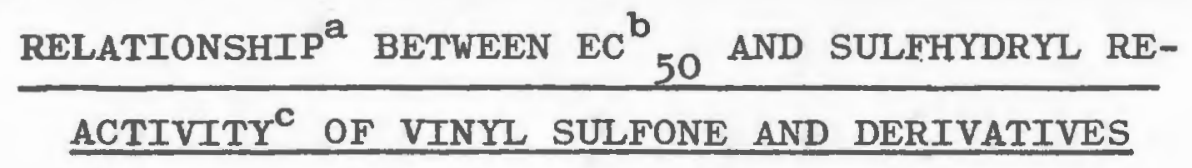

\begin{tabular}{|c|c|c|c|}
\hline IDENTIFICATION & & $\mathrm{EC}_{50}$ & $\begin{array}{l}\text { SULFHYDRYL } \\
\text { REACTIVITY }\end{array}$ \\
\hline VINYL SULFONE & $\mathrm{CH}_{2}=\mathrm{CH}-\mathrm{SO}_{2}-\mathrm{CH}=\mathrm{CH}_{2}$ & 1.0 & 0.1990 \\
\hline URI \#793 & $-\mathrm{SO}_{2}-\underset{\mathrm{C} 1}{\mathrm{C}}=\underset{\mathrm{C} 1}{\mathrm{CH}}$ & 2.0 & 0.1948 \\
\hline URI \#744 & $\mathrm{SO}_{2}-\mathrm{CH}=\mathrm{CH}_{2}$ & 8.0 & 0.0607 \\
\hline URI \#760 & $\mathrm{CH}_{2}-\mathrm{SO}_{2}-\mathrm{CH}=\mathrm{CH}_{2}$ & 11.0 & 0.0321 \\
\hline URI \#718 & $\mathrm{CH}_{3}-\mathrm{SO}_{2}-\mathrm{CH}=\mathrm{CH}_{2}$ & 18.0 & 0.0129 \\
\hline DES & $\mathrm{CH}_{3}-\mathrm{CH}_{2}-\mathrm{SO}_{2}-\mathrm{CH}_{2}-\mathrm{CH}_{3}$ & 1600.0 & 0.00174 \\
\hline
\end{tabular}
a. Correlation coefficient for $\mathrm{EC}_{50}$ vs. sulfhydryl re-
activity is 0.933 .

b. Calculated concentration, in parts per million, which will kill fifty percent of a population of A.glabratus

c. Expressed as micromoles cysteine reacted/micromoles inhibitor. 
TABLE 3

$$
\frac{\text { RELATIONSHIP BETWEEN EC }{ }_{50}^{\text {a AND SULFHYDRYL }}}{\frac{\text { REACTIVITY OF N-TRITYLMORPHOLINE AND }}{\text { N-TRIPHENYLACETYL MORPHOLINE }}}
$$

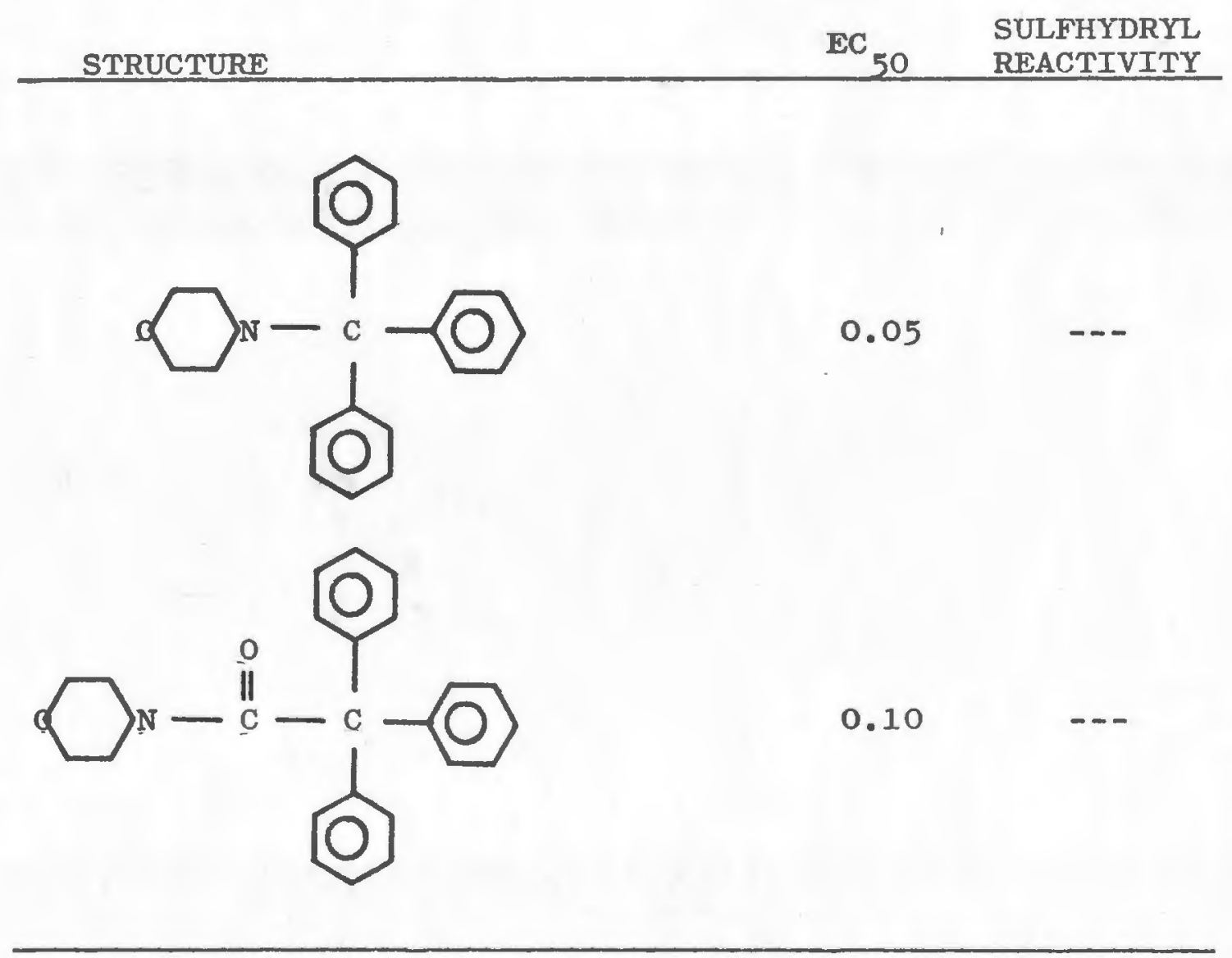

a. Calculated concentration, in parts per million, which will kill fifty percent of a population of $A$. glabratus.

b. Expressed as micromoles cysteine reacted/micromoles inhibitor. 


\section{AFFINITY OF VINYL SULFONE AND DERIVATIVES FOR SULFHYDRYL GROUPS OF CYSTEINE}

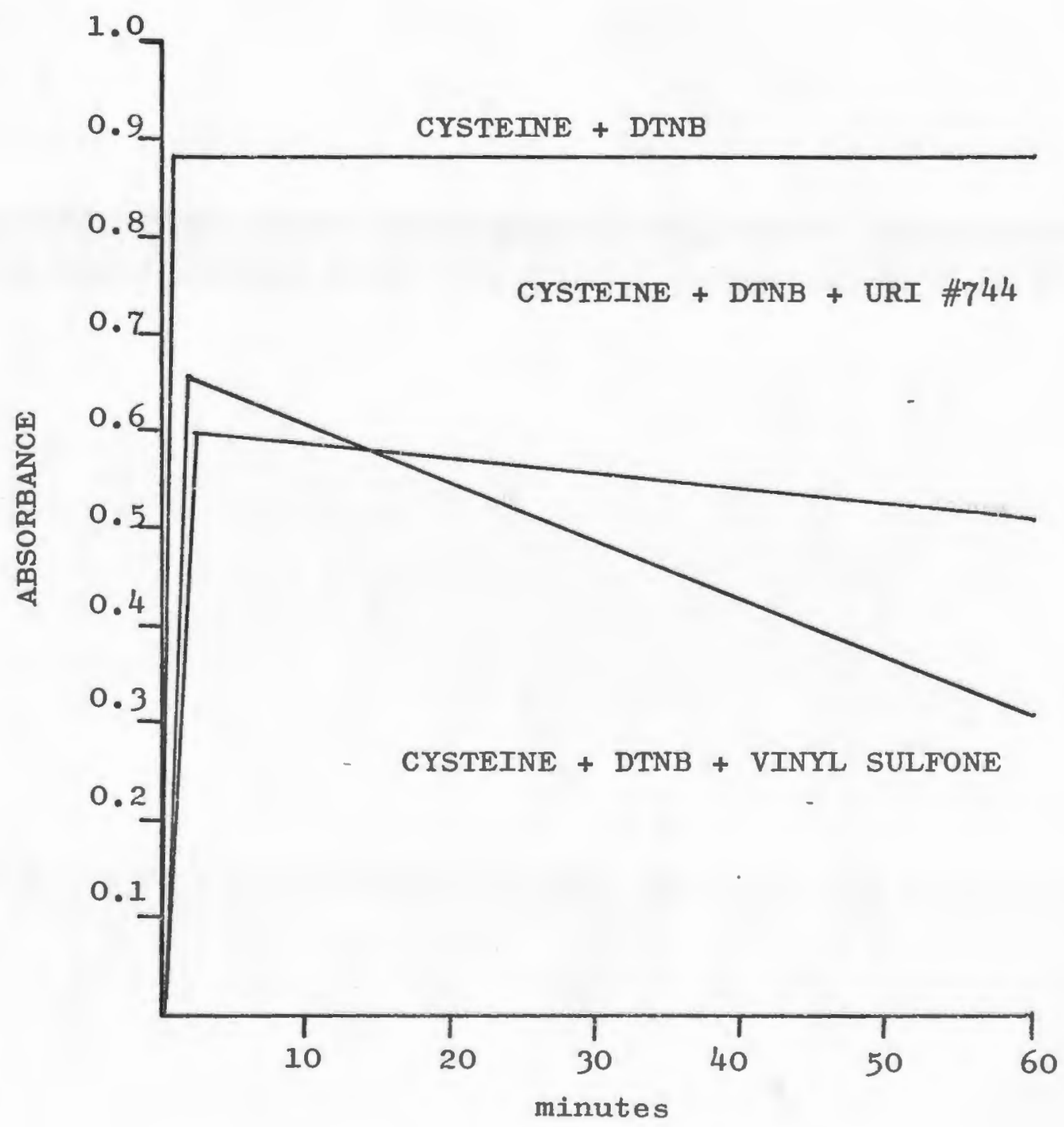




\section{B. ENZYME STUDIES}

Table 4 represents the effect of vinyl sulfone on the activity of 1.08 units of porcine malic dehydrogenase $(\mathrm{MDH})$. A dose dependent relationship between activity and concentration can be seen. Vinyl sulfone, at a concentration of $1.1 \times 10^{-3} \mathrm{M}$, exerts negligible inhibitory effects on $\mathrm{MDH}$ while a concentration of $3.4 \times 10^{-3} \mathrm{M}$ vinyl sulfone inhibits the activity $50 \%$ and $5.6 \times 10^{-3} \mathrm{M}$ vinyl sulfone produces a $77 \%$ inhibition of activity. Figure 4 shows the effect of vinyl sulfone and diethyl sulfone on the total reaction time of the malic dehydrogenase system. In the presence of oxalacetate and $\mathrm{NADH}, 1.08$ units of malic dehydrogenase catalyzes the complete reduction of oxalacetate to malate in 90 seconds. Vinyl sulfone $\left(3.3 \times 10^{-3} \mathrm{M}\right)$ increases the complete reduction time to 120 seconds. The same system, in the presence of vinyl sulfone and $6.9 \times 10^{-3} \mathrm{M}$ cysteine, produces a decrease in the complete reduction time to 30 seconds. In the presence of diethyl sulfone, the same $\mathrm{MDH}$ system completely reduces the oxalacetate in 15 seconds. Addition of oxalacetate to any one of the test situations produces a continuation of the reduction reaction at the same rate.

The effect of substrate (oxalacetate) concentration on the in vitro activity of $\mathrm{MDH}$ is shown in Table 5. A dose dependent relationship exists between malic dehydrogenase activity and oxalacetate concentration. Increasing the concentration of oxalacetate from $1.9 \times 10^{-3} \mathrm{M}$ to 


\section{TABLE 4}

EFFECT OF VINYL SULFONE ON THE ACTIVITY ${ }^{a}$ OF

\section{PURIFIED PORCINE MALIC DEHYDROGENASE}

\begin{tabular}{lccc}
$\begin{array}{l}\text { VINYL SULFONE } \\
\text { CONCENTRATION }\end{array}$ & $\begin{array}{c}\text { REACTION } \\
\text { RATE }\end{array}$ & INHIBITION & P \\
0.00 & $4.0^{\mathrm{b}} \pm .08$ & 0.00 &.- \\
$1.1 \times 10^{-3} \mathrm{M}$ & $3.9^{\mathrm{b}} \pm .04$ & 3 & N.S. \\
$2.2 \times 10^{-3} \mathrm{M}$ & $2.8^{\mathrm{b}} \pm .00$ & 30 & P 0.05 \\
$3.4 \times 10^{-3} \mathrm{M}$ & $2.0^{\mathrm{b}} \pm .00$ & 50 & P 0.05 \\
$4.5 \times 10^{-3} \mathrm{M}$ & $1.6^{\mathrm{b}} \pm .01$ & 61 & P 0.05 \\
$5.6 \times 10^{-3} \mathrm{M}$ & $1.3^{\mathrm{b}} \pm .02$ & 77 & P 0.05 \\
\hline
\end{tabular}

a. Expressed as the slope of the curve of the reaction between MDH and oxalacetate followed on a linear log recorder.

b. Represents the mean and standard error of five determinations.

c. Not statistically significant. P 0.05 . 
FIGURE 4

EFFECT OF VINYL SULFONE, DIETHYL SULFONE, AND

CYSTEINE + VINYL SULFONE ON THE IN VITRO AC-

TIVITY ${ }^{a}$ OF PURIFIED PORCINE MALIC DE-

HYDROGENASE ${ }^{6}$

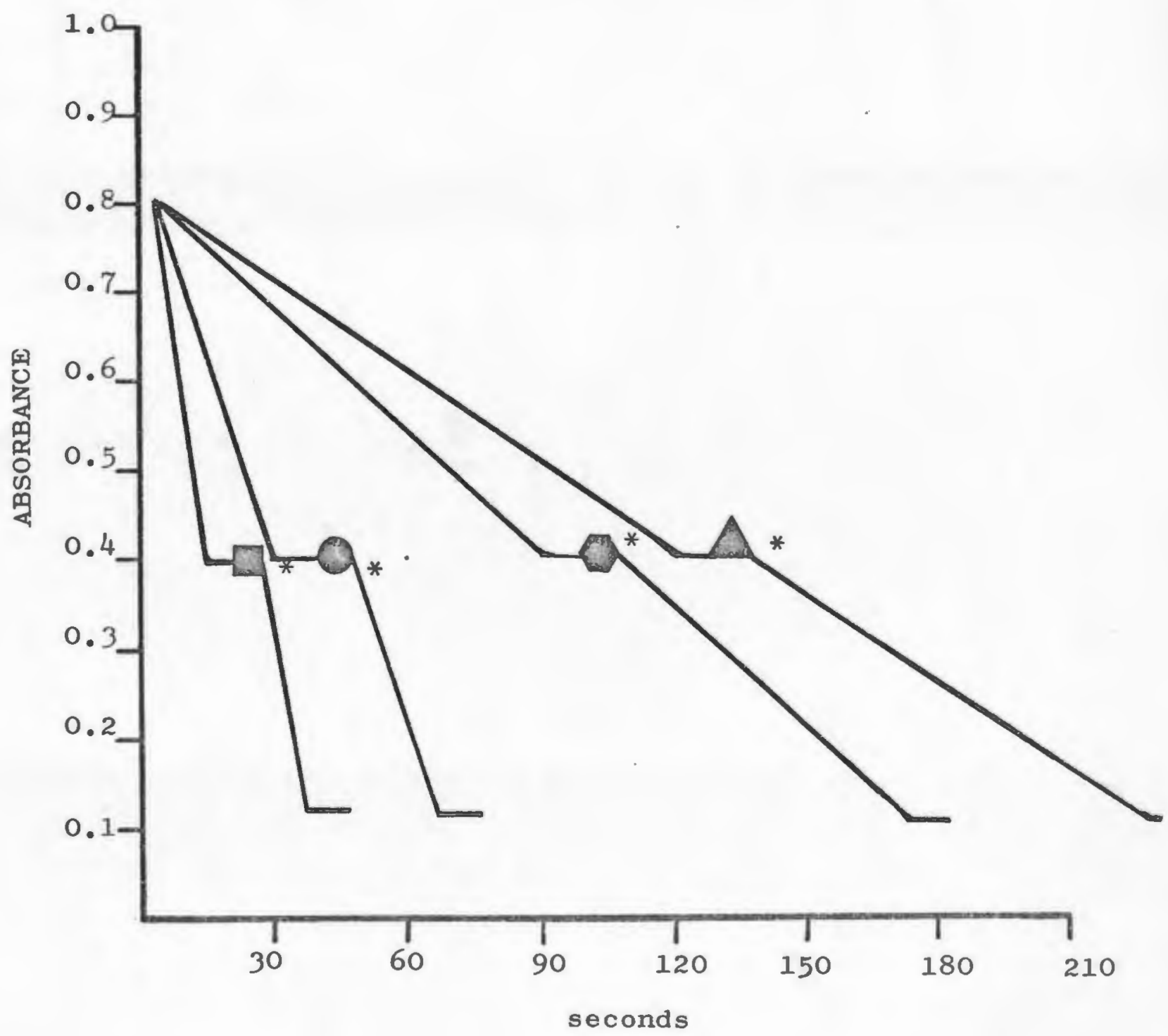

1 STANDARD $\triangle 3.33 \times 10^{-3} \mathrm{M}$ VS $6.85 \times 10^{-3} \mathrm{M}$ CYSTEINE + $3.33 \times 10^{-3} \mathrm{M}$ vs, $3.33 \times 10^{-3} \mathrm{M}$ DES, *2nd Add. OXAlaCETATE.

a. Expressed as the rate of oxidation of NADH

b. 1.08 units $\mathrm{MDH}$ 
TABLE 5

EFFECT OF SUBSTRATE CONCENTRATION ON THE IN VITRO ACTIVITY OF PURIFIED PORCINE MALIC DEHYDROGENASE ${ }^{\text {b }}$

$\begin{array}{lc}\begin{array}{c}\text { OXALACETATE } \\ \text { CONCENTRATION }\end{array} & \begin{array}{c}\text { REACTION } \\ \text { RATE }\end{array} \\ 1.9 \times 10^{-3} \mathrm{M} & 3.6 \\ 3.8 \times 10^{-3} \mathrm{M} & 3.2 \\ 7.6 \times 10^{-3} \mathrm{M} & 2.0 \\ 1.5 \times 10^{-2} \mathrm{M} & 1.6\end{array}$

a. Expressed as the slope of the curve of the reaction between $\mathrm{MDH}$ and oxalacetate followed on a linear log recorder.

b. 1.08 units of $\mathrm{MDH}$. 
to $1.5 \times 10^{-2} \mathrm{M}$ decreases the activity of malic dehydrogenase by $56 \%$.

\section{OXYGEN UPTAKE STUDIES IN A. GLABRATUS AND RAT TISSUE}

The effect of vinyl sulfone or beta-nitrostyrene on $\underline{\text { in }}$ vitro endogenous respiration in the snail A. Elabratus is shown in Table 6. A concentration of $3.3 \times 10^{-3} \mathrm{M}$ vinyl sulfone exhibits no significant effect on endogenous respiration while a concentration of $3.3 \times 10^{-3} \mathrm{M}$ beta-nitrostyrene produces a significant ( $P$ 0.05) $36 \%$ decrease in endogenous respiration.

The effect of in vitro vinyl sulfone on the endogenous respiration of liver and brain slices of female rats is presented in Table 7. A concentration of $3.3 \times 10^{-3} \mathrm{M}$ vinyl sulfone produces no effect on endogenous respiration while a concentration of $1.7 \times 10^{-3} \mathrm{M}$ vinyl sulfone exhibits significant (P 0.05) inhibitory effects on endogenous respiration in brain slices while producing no effect on endogenous respiration in liver slices.

Table 8 shows endogenous respiration in brain slices of female rats treated in vivo with vinyl sulfone. An intraperitoneal dose of $20 \mathrm{mg} / \mathrm{kg}$ vinyl sulfone produces no significant change in endogenous respiration 30 minutes after treatment.

The effect of in vitro vinyl sulfone on pyruvate metabolism in brain homogenates of male rats is shown in Table 9. A concentration of $9.7 \times 10^{-4} \mathrm{M}$ vinyl sulfone produces a significant ( $\mathrm{P} \quad 0.05) \quad 53 \%$ decrease in pyruvate metabolism. Table 10 represents the effect of in vitro 
TABLE 6

EFFECT OF VINYL SULFONE ON IN VITRO ENDOGENOUS RESPIRATION

IN THE SNAIL, AUSTRALORBIS GLABRATUS

ENDOGENOUS ${ }^{a}$

RESPIRATION

CONTROL $^{\mathrm{b}}$

$3.3 \times 10^{-3} \mathrm{M}$

VINYL SULFONE

$3.3 \times 10^{-3} \mathrm{M}$ BETA-NITROSTYRENE
$2.09 \pm .06^{\mathrm{f}} \quad 0.00$

$2.11 \pm .08^{f}$

$+1$

N.S. ${ }^{\text {e }}$

$1.34 \pm .19^{f}$

$-36$

$P 0.05$

a. Expressed as the $\mathrm{QO}_{2}$.

b. Control samples treated with absolute ethanol.

c. Vinyl sulfone dissolved in $0.1 \mathrm{ml}$ absolute ethanol.

d. Beta-nitrostyrene, a known inhibitor of oxygen uptake in A. glabratus, dissolved in $0.1 \mathrm{ml}$ absolute ethanol.

e. Not statistically significant. P 0.05.

f. Represents the mean and standard error of five determinations. 


\begin{tabular}{|c|c|c|c|c|c|c|}
\hline $\begin{array}{l}\text { VINYL SULFONE } \\
\text { CONCENTRATION }\end{array}$ & $\begin{array}{l}\text { ENDOGENOUS }^{a} \\
\text { RESPIRATION }\end{array}$ & $\begin{array}{l}\text { LIVER } \\
\not \\
\text { CHANGE }\end{array}$ & $\mathbf{P}$ & $\begin{array}{l}{ }^{A} \text { ENDOGENOUS } \\
\text { RESPIRATION }\end{array}$ & $\begin{array}{c}\text { BRAIN } \\
\not \\
\text { CHANGE }\end{array}$ & $\mathbf{P}$ \\
\hline $0.00^{f}$ & $4.2^{c} \pm .19$ & --- & $-\infty$ & $5.1^{d} \pm .46$ & --- & --- \\
\hline $3.3 \times 10^{-4} \mathrm{M}$ & $4.2^{c} \pm .21$ & --- & --- & $4.7^{d} \pm .19$ & -8 & N.S. ${ }^{e}$ \\
\hline $1.7 \times 10^{-3} \mathrm{M}$ & $3.9^{c} \pm .38$ & -7 & N.S. ${ }^{\ominus}$ & $2.9^{d} \pm .18$ & -43 & P 0.05 \\
\hline
\end{tabular}

a. Expressed as the $\mathrm{QO}_{2}$.

b. Dissolved in absolute ethanol.

c. Represents the mean and standard deviation of four determinations run in duplicate.

d. Represents the mean and standard error of five determinations run in duplicate.

e. Not statistically significant. p 0.05 .

f. Absolute ethanol used as control. 
TABLE 8

ENDOGENOUS RESPIRATION IN BRAIN SLICES OF FEMALE

RATS TREATED IN VIVO WITH VINYL SULFONE

\begin{tabular}{lccc} 
& $\begin{array}{c}\text { ENDOGENOUS }^{a} \\
\text { RESPIRATION }\end{array}$ & $\begin{array}{c}\phi \\
\text { CHANGE }\end{array}$ & P \\
CONTROL $^{\mathrm{b}}$ & $6.8^{\mathrm{e}} \pm .67$ & $-\ldots$ & \\
TREATED $^{\mathrm{c}}$ & $7.0^{\ominus} \pm .53$ & +3 & N.S. $^{\mathrm{d}}$ \\
\hline
\end{tabular}

a. Expressed as the $\mathrm{QO}_{2}$.

b. Control animals received $5 \%$ ethanol ( $1 \mathrm{ml} / \mathrm{kg}$ ) intraperitoneal1y.

c. Treated animals received vinyl sulfone (20 $\mathrm{mg} / \mathrm{kg}$ ) intraperitoneally in a $5 \%$ ethanol vehicle.

d. Not statistically significant. $P 0.05$.

e. Represents the mean and standard error of four determinations run in duplicate. 
TABLE 9

EFFECT OF IN VITRO VINYL SULFONE ON PYRUVATE

METABOLISM IN BRAIN HOMOGENATES OF MALE RATS

VINYL SULFONE ${ }^{C}$ CONCENTRATION

\begin{tabular}{|c|c|c|c|}
\hline $\begin{array}{l}\text { PYRUVATE } \\
\text { CONTROL }\end{array}$ & $\begin{array}{c}\text { METABOLISM }^{a} \\
\text { TREATED }\end{array}$ & $\begin{array}{c}\% \\
\text { CHANGE }\end{array}$ & $\mathbf{P}$ \\
\hline $2.5^{b} \pm .40$ & $2.3 \pm \cdot 10$ & -7 & N.S. ${ }^{e}$ \\
\hline $1.9^{b} \pm .35$ & $1.8 \pm .44$ & -5 & N.S. ${ }^{e}$ \\
\hline $2.5^{b} \pm .40$ & $1.5 \pm .03$ & -39 & N.S. ${ }^{e}$ \\
\hline $1.9^{b} \pm .35$ & $0.9 \pm .36$ & -53 & $P 0.05$ \\
\hline
\end{tabular}

$9.7 \times 10^{-4} \mathrm{M}$

a. Expressed as microliters of oxygen taken up per milligram wet tissue per thirty minutes.

b. Represents the mean and standard error of three determinations run in quadruplicate.

c. Dissolved in absolute ethanol.

d. Control samples treated with absolute ethanol.

e. Not statistically significant. $P 0.05$. 
EFFECT OF IN VITRO VINYL SULFONE ON PYRUVATE

METABOLISM IN LIVER HOMOGENATES OF MALE RATS

VINYL SULFONE ${ }^{C}$ CONCENTRATION
PYRUVATE METABOLISM ${ }^{a}$ CONTROL TREATED

$$
2 \cdot 3^{b} \pm .14
$$$$
2.2 \pm .09-2 \quad \text { N.S. }
$$

$1.2 \times 10^{-4} \mathrm{M}$

$2 \cdot 3^{b} \pm \cdot 19$

$2.2 \pm .39-5 \quad$ N.S. ${ }^{\text {e }}$

$2.4 \times 10^{-4} \mathrm{M}$

$2.5^{b} \pm .00$

$2.2 \pm .03-13 \quad$ N.S.e

$9.7 \times 10^{-4} \mathrm{M}$

$2.1^{b} \pm .36$

$1.5 \pm .24-29 \quad$ N.S. ${ }^{\text {e }}$

$2.4 \times 10^{-3} \mathrm{M}$

$1.1 \pm .14 \quad-53 \quad$ P 0.05 
TABLE 11

\author{
PYRUVATE METABOLISM ${ }^{a}$ IN LIVER, KIDNEY, AND BRAIN \\ HOMOGENATES OF MALE RATS TREATED IN VIVO \\ WITH VINYL SULFONE
}

SAMPLE CONTROE

$\begin{array}{llll}\text { LIVER }^{c} & 2.23 \pm 0.09 & 2.63 \pm 0.17^{\mathrm{b}} & \text { N.S. }{ }^{f} \\ \text { KIDNEY }^{\mathrm{C}} & 3.06 \pm 0.36 & 3.02 \pm 0.35 & \text { N.S. } \\ \text { BRAIN }^{\mathrm{d}} & 1.30 \pm 0.06 & 1.69 \pm 0.34 & \text { N.S. }\end{array}$

a. Expressed as microliters of oxygen taken up per milligram wet tissue per thirty minutes.

b. Represents the mean of four assays run in triplicate.

c. Rats were treated with vinyl sulfone $(10 \mathrm{mg} / \mathrm{kg})$ and sacrificed 120 minutes after treatment.

d. Rats were treated with vinyl sulfone $(20 \mathrm{mg} / \mathrm{kg})$ and sacrificed 30 minutes after treatment.

e. Control rats received dosage vehicle, $0.15 \% \mathrm{CMC}$.

f. Statistically not significant. P 0.05 . 
vinyl sulfone on pyruvate metabolism in liver homogenates of male rats. A concentration of $2.4 \times 10^{-3} \mathrm{M}$ vinyl sulfone produces a significant ( $\mathrm{P} 0.05)$ 53\% decrease in pyruvate metabolism. In both cases, the inhibition of pyruvate metabolism is dose dependent. Lower concentrations of vinyl sulfone exhibit no signficant inhibitory effects on pyruvate metabolism.

Table 11 shows pyruvate metabolism in liver, kidney, and brain homogenates of male rats treated in vivo with vinyl sulfone. An intraperitoneal dose of $10 \mathrm{mg} / \mathrm{kg} \cdot \mathrm{vinyl}$ sulfone produces no significant change in pyruvate metabolism of liver or kidney homogenates 120 minutes after treatment. Similarly, an intraperitoneal dose of $20 \mathrm{mg} / \mathrm{kg}$ vinyl sulfone produces no significant effect on pyruvate metabolism in brain homogenates 30 minutes after treatment.

D. LD $_{50}$ AND PROTECTION STUDIES

Table 12 shows data representing an $\mathrm{LD}_{50}$ study done on vinyl sulfone using female rats. An intraperitoneal dose of $3.5 \mathrm{mg} / \mathrm{kg}$ produces $100 \%$ mortality with an average time to death of 5 days while a dose of $2.5 \mathrm{mg} / \mathrm{kg}$ produces $40 \%$ mortality with an average time to death of 7 days. An intraperitoneal pretreatment of $250 \mathrm{mg} / \mathrm{kg}$ cysteine $\mathrm{HCl}$, 15 minutes prior to an intraperitoneal administration of $6 \mathrm{mg} / \mathrm{kg}$ vinyl sulfone, protects all anjmals against the toxic effects of $6 \mathrm{mg} / \mathrm{kg}$ vinyl sulfone. 
Table 13 shows protection studies done with viny1 sulfone using male rats. An intraperitoneal dose of $6 \mathrm{mg} /$ kg vinyl sulfone produces $100 \%$ mortality with an average time to death of one day while an intraperitoneal pretreatment of $250 \mathrm{mg} / \mathrm{kg}$ cysteine $\mathrm{HCl}, 15$ minutes prior to an intraperitoneal administration of $18 \mathrm{mg} / \mathrm{kg}$ vinyl sulfone, fails to protect any of the animals from the toxic effects of vinyl sulfone. A subcutaneous pretreatment of $250 \mathrm{mg} /$ kg cysteine HCl, forty-five minutes prior to an intraperitoneal administration of $6 \mathrm{mg} / \mathrm{kg}$ vinyl sulfone, protects one out of five animals from the toxic effects of vinyl sulfone and extends the average time to death of the four dead animals from one to six days.

E. HEMATOLOGY, BLOOD CHEMISTRY, AND URINE ANALYSES

The effect of a dose of vinyl sulfone, 3.3 times that of the $\mathrm{LD}_{50}$, on the hematocrit of male rats is shown in Table 14. An intraperitoneal dose of $10 \mathrm{mg} / \mathrm{kg}$ produces a significant ( $P \quad 0.05)$ increase in the hematocrit of male rats 90 minutes after treatment. Concurrent with the increase in hematocrit in male rats, a copius edema of the peritoneal cavity is observed.

The hepatotoxicity of vinyl sulfone in female rats is shown in Table 15. An intraperitoneal dose of $2 \mathrm{mg} / \mathrm{kg}$ vinyl sulfone does not produce any significant change in the serum glutamic pyruvate transaminase or serum glutamic oxalacetic transaminase levels 72 hours after treatment. 
TABLE 12

DETERMINATION OF AN APPROXIMATE INTRAPERITONEAL

LD $_{50}$ FOR VINYL SULFONE IN FEMALE RATS

\begin{tabular}{|c|c|c|}
\hline${ }^{\mathrm{E}}$ SULFONE & $\frac{\text { NO. DEAD ANII }}{\text { NO. TREATED Al }}$ & \\
\hline
\end{tabular}

2.5

3.5

6.0

$\frac{6.0}{+} \underset{+}{250 \mathrm{mg} / \mathrm{kg}^{-} \text {cysteine }} \mathrm{b}^{\mathrm{b}}$
$2 / 5$

$5 / 5$

$5 / 5$

$0 / 5$
7 days

5 days

1.8 days

. Dissolved in $5 \%$ ethanol.

b. Cysteine $\mathrm{HCl}$ adjusted to $\mathrm{pH} 7.3$ with $\mathrm{NaOH}$ and administered intraperitoneally 15 minutes prior to administration of vinyl sulfone. 
TABLE 13

DETERMINATION OF THE EFFECTS OF VINYL SULFONE ON

MALE RATS PRETREATED SUBCUTANEOUSLY OR

INTRAPERITONEALLY WITH CYSTEINE

HYDROCHLORIDE

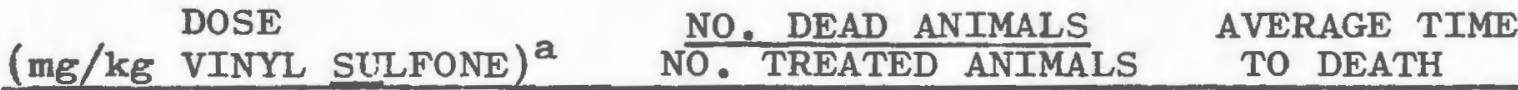

6

$\stackrel{6}{\stackrel{6}{+}} \underset{\substack{+250 \mathrm{mg} / \mathrm{kg}_{\text {CYSTEINE }}^{\mathrm{b}}}}{\text { SUBCUTANEOUSLY }}$

18

$+$

$250 \mathrm{mg} / \mathrm{kg}^{+}$CYSTEINE ${ }^{\mathrm{C}}$

INTRAPERITONEALLY

SUBCUTANEOUSLY
$5 / 5$

$4 / 5$

$5 / 5$

0.7 days
1 day

6 days

$\begin{array}{lcc}18 & 5 / 5 & 0.7 \text { days } \\ 250 \mathrm{mg} / \mathrm{kg} \text { CYSTEINE } & \mathrm{c} \\ \text { INTRAPERITONEALLY } & \end{array}$

a. Dissolved in $5 \%$ ethanol.

b. Adjusted to $\mathrm{pH} 7.3$ with $\mathrm{NaOH}$ and administered fortyfive minutes prior to the intraperitoneal administration of vinyl sulfone.

c. Adjusted to $\mathrm{pH} 7.3$ with $\mathrm{NaOH}$ and administered fiften minutes prior to the intraperitoneal administration of vinyl sulfone. 
TABLE 14

EFFECT OF VINYL SULFONE ON THE

HEMATOCRIT OF MALE RATS

\begin{tabular}{llll} 
& HEMATOCRIT & P \\
\hline CONTROL $^{a}$ & $0.45^{c} \pm .01$ & - \\
TREATED $^{b}$ & $0.70^{c} \pm .01$ & P 0.05 \\
\hline
\end{tabular}

a. Control rats received $0.5 \%$ carboxymethylcellulose ( $1 \mathrm{ml} / \mathrm{kg}$ ).

b. $10 \mathrm{mg} / \mathrm{kg}$ intraperitoneally.

c. Represents the mean and standard error of four determinations run in duplicate. 
TABLE 15

HEPATOTOXICITY OF VINYL SULFONE IN FEMALE RATS

\begin{tabular}{llll} 
& CONTROL $^{\mathrm{a}}$ & TREATED $^{\mathrm{b}}$ & P \\
\hline SGOT & $25^{\mathrm{e}} \pm 6.6^{\mathrm{c}}$ & $17 \pm 4.0^{\mathrm{c}}$ & N.S. ${ }^{\mathrm{d}}$ \\
SGPT & $40^{\mathrm{e}} \pm 15.0^{\mathrm{c}}$ & $30 \pm 11.6^{\mathrm{c}}$ & N.S. \\
\hline
\end{tabular}

a. Control animals received $5 \%$ ethanol ( $1 \mathrm{ml} / \mathrm{kg}$ ) ip and were bled 72 hours after treatment.

b. Treated animals received $2 \mathrm{mg} / \mathrm{kg}$ vinyl sulfone ip in a $5 \%$ ethanol vehicle and were bled 72 hours after treatment.

c. Reitman-Franke1 units.

d. Not statistically significant.

e. Represents the mean and standard error of eight determinations. 


\begin{tabular}{lcccccc} 
& HEMATOCRIT & $\begin{array}{c}\text { BLOOD }^{\mathrm{a}} \\
\text { UREA NITROGEN }\end{array}$ & $\begin{array}{c}\text { URINARY }^{\mathrm{b}} \\
\text { VOLUME }\end{array}$ & $\begin{array}{c}\text { URINARY } \\
\text { PH }\end{array}$ & $\begin{array}{c}\text { URINARY } \\
\text { SUGAR }\end{array}$ & $\begin{array}{c}\text { URINARY }^{\mathrm{d}} \\
\text { ALBUMIN }\end{array}$ \\
\hline CONTROL $^{\mathrm{e}}$ & $0.40 \pm .01^{\mathrm{i}}$ & $26.4 \pm 1.7^{\mathrm{I}}$ & $16.2 \pm 1.0^{1}$ & 8.0 & NEGATIVE & NEGATIVE \\
TREATED $^{\mathrm{f}}$ & $0.37 \pm .02^{\mathrm{g}}$ & $83.4 \pm 2.6^{\mathrm{h}}$ & $8.3 \pm 2.5$ & 8.0 & NEGATIVE & NEGATIVE
\end{tabular}

a. Expressed as milligrams per $100 \mathrm{ml}$ blood.

b. Milliliters excreted per twenty-four hours.

c. Clinitest method utilized for urinary sugar determination.

d. Sulfosalicylic acid method utilized for urinary albumin determination.

e. Control rats received 5\% ethanol ip and urine samples collected over a twentyfour hour period starting forty-eight hours after administration of vinyl sulfone.

f. Treated rats recelved vinyl sulfone $(2 \mathrm{mg} / \mathrm{kg})$ intraperitoneally.

g. Not statistically significant. $P 0.05$.

h. Statistically significant. $P 0.05$.

i. Represents the mean and standard error of eight determinations. 
The effect of a sublethal dose of vinyl sulfone on the hematocrit and kidney function of male rats is shown in Table 16. An intraperitoneal dose of $2 \mathrm{mg} / \mathrm{kg}$ vinyl sulfone produces no significant change in hematocrit, urinary $\mathrm{pH}$, sugar or albumin; however, $2 \mathrm{mg} / \mathrm{kg}$ vinyl sulfone does produce a significant ( $P$ 0.05) $49 \%$ decrease in urinary output (volume) and a significant ( $P$ 0.05) $316 \%$ increase in blood urea nitrogen from $26.4 \mathrm{mg} \%$ to $83.4 \mathrm{mg} \%$. 


\section{v. DISCUSSION}

These data indicate that the mechanism of toxicity of vinyl sulfone in $A$. glabratus and albino rats is not, the inhibition of endogenous respiration in the tissues tested and that the mechanism of toxicity of vinyl sulfone is probably related to its reactivity with other important sulfhydryl groups.

A structural comparison of the three aliphatic compounds of the vinyl sulfone series (vinyl sulfone, URT \#718, and diethyl sulfone) suggests that decreased sulfhydryl reactivity and molluscicidal potency are correlated with alpha-beta unsaturations. A comparison of the aromatic vinyl suIfones URI \#793 and URI \#744 indicates that substitution by a phenyl group at the sulfone function decreases sulfhydryl reactivity and molluscicidal potency relative to the parent vinyl sulfone molecule. Substitution by a benzyl group, in which there is an intervening methylene group between the sulfur atom and the phenyl group, further decreases the sulfhydryl reactivity and molluscicidal potency. The halogenated vinyl sulfone, URI \#793, possesses significantly greater sulfhydryl reactivity and molluscicidal potency than URI \#744. It seems likely that the halogenation of the alpha-beta carbon atoms of various derivatives of vinyl sulfone would also increase the sulf- 
hydryl reactivity and molluscicidal potency in the same manner as the halogenation of the phenyl substituted compound. In general, it appears that, in this series of compounds, sulfhydryl reactivity and molluscicidal potency are decreased with bis substitution by aliphatic or aromatic functional groups and increased by halogenation of the alphabeta carbon atoms. The importance of the alpha-beta unsaturations is demonstrated by the high degree of sulfhydryl reactivity and molluscicidal potency exhibited by vinyl sulfone and the lack of sulfhydryl reactivity and molluscicidal potency exhibited by diethyl sulfone. Sulfhydryl reactivity is not an inherent characteristic of molluscicides since neither $\mathrm{N}$-tritylmorpholine nor $\mathrm{N}$-triphenylacetyl morpholine exhibit this characteristic.

The slow color decay seen in Figure 3 may be explained by the possible oxidation of the anion to the colorless DTNB molecule when the system of cysteine + DTNB is treated with vinyl sulfone or derivatives. The presence of cysteine in the standard (non-treated) system of cysteine + DTNB may stabilize the anion by preventing its oxidation. Alternatively, vinyl sulfone may condense with the anion to yield a colorless compound.

Malic dehydrogenase (MDH) is classified as a type A sulfhydryl enzyme by Webb (1966) and Pfleiderer (1969). Fondy et al. (1970) have shown that sulfhydryl groups exist at or near the active center of $\mathrm{MDH}$ and Gregory et al. (1971) have shown that MDH has at least two (and possibly three) sulfhydryl groups at or near the enzymatic active centers which are essential for activity. Anderton (1970) 
has shown that MDH contains at least $12-14$ sulfhydryl groups.

Since MDH is a sulfhydryl dependent enzyme, it is of interest to determine if vinyl sulfone inhibits the activity of $\mathrm{MDH}$. The inhibitory effect of vinyl sulfone is dose dependent as seen in Table 4. A dose of $3.3 \times 10^{-3} \mathrm{M}$ vinyl sulfone is required to inhibit $50 \%$ of the activity of 1.08 units of malic dehydrogenase. The apparent activation of MDH in the presence of cysteine and vinyl sulfone may be explained by the possible chelation of repressive trace metals by cysteine. The apparent activation of $\mathrm{MDH}$ by diethyl sulfone, however, cannot be explained in this manner. Since $3.3 \times 10^{-3} \mathrm{M}$ vinyl sulfone is required to inhibit $50 \%$ of the activity of 1.08 units of MDH while vinyl sulfone is molluscicidal at concentrations of one part per million or $8 \times 10^{-6} \mathrm{M}$, it is unlikely that the mechanism of toxicity of vinyl sulfone in the snail A. glabratus is the inhibition of malic dehydrogenase. An in vivo concentration of $3.3 \times 10^{-3} \mathrm{M}$ would be difficult to achieve in snails and other test animals. Furthermore, even if such a high concentration could be achieved, it would be unlikely that the in vivo concentration would produce the same degree of action as the in vitro concentration. The in vitro vinyl sulfone exerts its effect in the presence of one sulfhydryl compound while in vivo vinyl sulfone would have the ability to react with a multitude of amino, hydroxyl, and sulfhydryl compounds and would, therefore, exert decreased activity on 
the target receptor.

In the light of the above discussion, and the fact that Peters and Wakelin (1949) reported that the inhibitory action of vinyl sulfone on succinic, malic, and lactic dehydrogenase was low in comparison to its effect on pyruvate dehydrogenase, the inhibitory effect of vinyl sulfone on the sulfhydryl dependent enzyme MDH can be considered to be insignificant.

The absence of effects produced by $3.3 \times 10^{-3} \mathrm{M}$ viny 1 sulfone on the in vitro endogenous respiration of $\underline{A}$. glabratus indicates that the mechanism of toxicity of vinyl sulfone in the snail A. Elabratus is not the inhibition cellular respiration. A similar concentration of betanitrostyrene produces a significant decrease in endogenous respiration. The latter observation is similar to the results Louis-Ferdinand (1970) obtained when priming snail homogenates with succinate and ATP.

The statistically significant decrease in in vitro endogenous respiration of brain slices of female rats, and in the in vitro pyruvate metabolism of liver and brain homogenates of male rats, when treated with $10^{-3} \mathrm{M}$ vinyl sulfone, is of questionable pharmacological significance. The concentration required for activity would probably never be reached in the in vivo intracellular situation. The above data and the fact that no effect was seen on the endogenous respiration of liver slices of female rats or in the endogenous respiration and pyruvate metabolism of animals treated in vivo with vinyl sulfone, suggest 
that the mechanism of toxicity of vinyl sulfone in albino rats is not the inhibition of cellular respiration.

Vinyl sulfone is extremely toxic to albino rats. Anslow et a1. (1947) have reported an intravenous $L_{50}$ of $12 \mathrm{mg} / \mathrm{kg}$ and Christensen (1971) has reported an intraperitoneal $\mathrm{LD}_{50}$ of $35 \mathrm{mg} / \mathrm{kg}$. Smyth (1962) has reported an oral $\mathrm{LD}_{50}$ of $25-43 \mathrm{mg} / \mathrm{kg}$ for rats. Our results indicate that the intraperitoneal $\mathrm{LD}_{50}$ for male and female albino rats is approximately $3 \mathrm{mg} / \mathrm{kg}$. The discrepancies among $\mathrm{LD}_{50}$ 's possibly arise from differences in animal strain, poor suspending techniques, or impure samples of vinyl sulfone.

Intraperitoneal pretreatment of albino rats with cysteine hydrochloride prevents mortality when lethal doses of vinyl sulfone are given; however, subcutaneous pretreatment of albino rats with cysteine prior to treatment with vinyl sulfone simply increases the time to death. It is possible that vinyl sulfone reacts with cysteine sulfhydryl groups within the peritoneal cavity and this complexing is either irreversible (thereby protecting against the vesicant activity of vinyl sulfone on the peritoneal eavity) or reversible at a rate which allows detoxification of vinyl sulfone without toxic side effects. The dose of cysteine, however, is ten times the stoichiometric amount required to react with the dose of vinyl sulfone administered. The increase in the in vivo sulfhydryl pool by the subcutaneous pretreatment with cysteine produces an increase in the time 
to death and gives further support to the hypothesis that the toxic effects of vinyl sulfone are related to its sulfhydryl reactivity.

The rapid accumulation of fluid in the peritoneal cavity, increase in hematocrit, and death of male rats treated with doses of vinyl sulfone 3.3 times greater than the $\mathrm{LD}_{50}$ dose $(10 \mathrm{mg} / \mathrm{kg}$ ) may be attributed to hypovolemia produced by the vesicant action of vinyl sulfone in the peritoneal cavity. The fact that a $2 \mathrm{mg} / \mathrm{kg}$ dose of vinyl sulfone, administered intraperitoneally to albino rats, does not cause an increase in the SGOT, SGPT, and blood volume characteristics indicates that the toxic effect of a sublethal dose of vinyl sulfone in albino rats is not due to hepatotoxicity or hypovolemia. The three fold increase in blood urea nitrogen and the decreased urinary output produced by a sublethal dose indicates that the toxic effects of vinyl sulfone are probably produced by impaiment of renal function.

The impairment of renal function by sublethal doses of vinyl sulfone is not surprising since sulfhydryl containing enzymes are involved in many of the tubular transport mechanisms (Guyton, 1971). Clarkson (1972) cites evidence indicating that the kidney accumulates high concentrations of mercury which is a sulfhydryl reagent with a high affinity for the thiol groups involved in renal function. Landon and Forte (1971) have supported these observations by reviewing evidence for a membrane bound 
$\mathrm{Na}^{+}-\mathrm{K}^{+}$activated ATPase system associated with renal transport of $\mathrm{Na}^{+}$and $\mathrm{K}^{+}$. ATPase systems have been shown to be dependent on sulfhydryl groups.

As stated previously, these data lead to the view that vinyl sulfone does not exert its toxic effect as a result of the inhibition of endogenous respiration via the blockage of sulfhydryl dependent enzymes involved with the process but that sulfhydryl reactivity and toxicity are correlated in some other manner. The convulsions seen by Anslow et al. (1947), and in our investigations, following high doses of vinyl sulfone are probably due to CNS toxicity. The rapid death of albino rats, preceded by an increase in hematocrit, is probably due to changes in blood volume caused by the vosicant activity of vinyl sulfone while the increased blood urea nitrogen and decreased urinary output (volume) produced by sublethal doses of vinyl sulfone is probably due to the reaction of vinyl sulfone with integral membrane proteins involved in renal function.

It is difficult to believe that vinyl sulfone could act at the intracellular level when used as a molluscicide which is diluted, in large expanses of water, to a concentration of $10^{-7} \mathrm{M}$. It is not difficult to hypothesize, however, that the toxic action of vinyl sulfone on $\underline{A}$. glabratus may be due to its reactivity with sulfhydryl groups of integral membrane proteins involved with normal cellular function. Some data which supports this hypothesis 
are: a) vinyl sulfone does exhibit a high degree of vesicant activity and the toxicity of vinyl sulfone has been correlated with its sulfhydryl reactivity; b) LouisFerdinand (1968) has reported that some beta-nitrostyrenes exhibit potent molluscicidal activity whlle producing little or no inhibition of oxygen uptake in snail homogenates; c) the concentration of vinyl sulfone required to inhibit a typical sulfhydryl dependent enzyme involved in cellular respiration is so high that it is unlikely that such a concentration could be reached in the in vivo situation unless the compound were concentrated by a particular physiological process; d) vinyl sulfone has been shown to exhibit a high degree of reactivity with hydroxyl and amino groups of proteinaceous compounds (Ford-Moore et al. 1950).

de Villiers (1963) has stated that most molluscicides exhibit a mode of action characterized by either interference with the osmoregulatory system of the snail or interference with enzyme systems which are dependent on sulfhydryl groups. In view of this statement, and the above hypothesis, it seems possible that the toxic effect of vinyl sulfone on A. Elabratus is produced by its reactivity with membrane bound proteins. This toxicity could be manifested in many ways. It is possible that, similar to the action of sublethal doses in albino rats, vinyl sulfone causes impairment of renal function in the snail and prevents the normal excretion of uric acid. It is also possible that 
vinyl sulfone produces changes in electrolyte balances due to its vesicant activity. 


\section{SUMMARY AND CONCLUSIONS}

1. Vinyl sulfone and derivatives exhibit a high degree of sulfhydryl reactivity wich is correlated with molluscicidal potency.

2. High concentrations of vinyl sulfone are necessary to inhibit malic dehydrogenase.

3. The toxic action of vinyl sulfone on A. Elabratus and albino rats is not due to the inhibition of sulfhydryl dependent enzymes involved in cellular respiration. The concentration required to achieve such an effect is so high that it is unlikely that this concentration would be reached in the in vivo intracellular situation.

4. Vinyl sulfone is extremely toxic to albino rats and this toxicity is related to its sulfhydryl reactivity.

5. The toxic effect of sublethal doses of vinyl sulfone in albino rats is caused by impairment of renal function leading to uremia while the toxic effect of doses of vinyl sulfone 3.3 times greater than the $\mathrm{LD}_{50}$ dose is probably due to hypovolemia caused by the vesicant activity of vinyl sulfone in the peritoneal cavity.

6. An hypothesis is made that the molluscicidal activity of vinyl sulfone and derivatives may be due to the reactivity of these compounds with integral membrane proteins involved in normal cell function. 


\section{REFERENCES}

Aicheneg6, P.C.: Chemagro Corp., U.S. Patent \#3,144,383. Through Chem. Abst. 58:9404A, 1960.

Anderton, B.H.: Alkylation studies on a reactive histidine in pig heart malic dehydrogenase. Fed. Eur. Biochem. 12:65-75, 1970.

Anslow, W.P., Karnofsky, A., Val Jager, B., and Smith, H.W.: The intravenous, subcutaneous, and cutaneous toxicity of bis (beta-chloroethyl) sulfide (mustard gase) and of various derivatives. J. Pharmaco1. Exp. Therap., 93:1-9, 1948.

Baker, D.R., Giolito, S.L., and Arnekley, D.R.: Bis (2-halovinyl) sulfone microbiocide. U.S. Patent \#3,268,391. Through Chem. Abst. 65:19248A, 1966.

Berg, C.0.: The fly that eats the snail that spreads disease. The Smithsonian Sept.:9-17, 1971.

Bond, H.: Personal communication. 1971.

Boyce, C.B., Crosland, N.O., and Shiff, C.J.: The molluscicidal activity of $\mathrm{N}$-tritylmorpholine. Nature (London) 212:614-617, 1966.

Brown, V.K., Stevenson, D.E., and Walker, A.I.T.: Toxicological studies with the molluscicide N-tritylmorpholine. Bull W.H.O. $37: 73-77,1967$.

Buckley, G.D., Charlish, J.L., and Rose, J.D.: Aliphatic nitro compounds part XVII. Reaction of nitroparafins with unsaturated sulfones. J. Chem. Soc. 44:1514-17, 1947.

Chang, C.C., Lu, P.N., Wang, and Chuang, S.T.: A comparison of the effects of various sulfhydryl reagents on neuromuscular transmission. Eur. J. Pharmacol. 11(2):195-203, 1970.

Clarkson, T.W.: The pharmacology of mercury compounds. Ann. Rev. Pharmaco1. 12:375-406, 1972.

Christensen, H.: Annual list of toxic substances. National Institute of Occupational Safety and Health, Washington, D.C., 500 pps, 1971.

Coles, G.C.: Isoenzymes of snail livers-I. Hydrolyzing enzymes and peroxidases. Comp. Biochem. Physio1. 29:403-411, 1969a. 
Coles, G.C.: Isoenzymes of snail Iivers-II. Dehydrogenases. Comp. Biochem. Physiol. 31:1-14, 1969b.

Conn, E.E., and Stumpf, P.K.: Outlines in biochemistry. John Wiley and Sons, New York, N.Y. 468 pps, 1967.

Cordier, C., and Cordier, D.: Mode of action of bis(2-chloroethyl) sulfone on cardiovascular system. Effects of hydrolysis products. Compt. Rend. Soc. Biol. 144:540-42, 1950.

Deutsch, W.: J. Physiology 87:56P, 1936.

de Villiers, J.P.: Structure and activity of molluscicides. The phenacyl halides, a group of potentially useful molluscicides. Bull W.H.0. 29:424-27, 1963.

Emerson, D.N.: Carbohydrate oriented metabolism of Planorbis corneus (mollusca planorbidae) during starvation. Comp. Biochem. Physio1. 22:571-79, 1967 .

Dixon, W.J., and Massey, F.J.: Introduction to statistical analysis. McGraw Hill Book Co., New York, N.Y., 638 pps, 1951.

Duncan, J., and Pav1ık, J.W.: Effects of structural rearrangements on the molluscicidal activity of certain fluorinated aromatic compounds. Bul1 W.H.O. 42:820-25, 1971.

Ellman, G.L.: Tissue sulfhydryl groups. Arch. Biochem. Biophys. $82: 70-77,1958$.

Fondy, P., Kitto, G.B., and Driscoll, G.A.: Comparison of thiol peptides of heart mitochondrial malic dehydrogenase from pig, chicken, and tuna. Biochem. J. 9:1001-10, 1970.

Faulkner, W.P., and King, J.W.: Manual of clinical laboratory procedures. Cleveland, Chemical Rubber Co., 200 pps, 1970.

Ford-Moore, A.H., Peters, R.A., and Wakelin, R.W.: The fission of thioether linkage in certain beta-sulphonylsulphides. J. Chem. Soc. 47:1754-57, 1950.

Ford-Moore, A.H.: Divinyl sulfone and allied compounds. J. Chem. Soc. 46:1514-17, 1949 .

Grant, W.M., and Kinsey, V.E.: Factors influencing the inactivation of urease by alkylating agents. J. Biol. Chem. 165:485$93,1946$.

Gregory, E.M., Yost, F.J., Rorhbach, M.S., and Harrison, J.H.: Selective chemical modification of malic dehydrogenase, J. Biol. Chem. 246:5491-96, 1971.

Guyton, A.C.: Textbook of medical physiology, W.B. Saunders Co., Philadelphia, Pa., 1025 pps, 1971. 
Haugaard, N., Lee, N.H., Kostrzewa, R.S., Horm, R., and Haugaard, E.: The role of sulfhydryl groups in oxidative phosphorylation and ion transport by rat liver mitochondria. Biochem. Biophys. Acta. 172(2):198-204, 1969.

Hegner, D.: Functional importance of sulfhydryl groups in membranes of lysosomal granules of bovine polymorphonuclear leucocytes, Naunyn Schmiedelbergs Arch. Pharmako1. Exp. Pathol. 261:239-51, 1968 .

Ishak, M.M.: Studies on the mode of action of some molluscicides in the snail B. alexandrina. Gen. Pharmaco1. 1(2):201-8, 1970.

Jobin, W.R., and Gladwin, O.U.: Chemical control of A. glabratus. U.S. Public Health Service Public Health Report $82: 63-71,1967$.

Jordan, P., and Webbe, G.: Human schistosomiasis. Charles C. Thomas, Springtield, I11., 212 pps, 1969.

Knauf, P.A., and Rothstein, A.: Chemical modification of membranes. J. Gen. Physiol. 58:211-23, 1971.

Kornicker, L.S.: Predation of schistosomiasis vector snails by ostracoids. Sci. 175:1258-59, 1972.

Lam, K.W.: Sulfhydryl group involvement in a soluble energy transfer factor of the oxidative phosphorylation system. Arch. Biochem. Biophys. 123:642-43, 1968.

Landon, E.J., and Forte, L.R.: Cellular mechanisms in renal pharmacology. Ann. Rev. Pharmacol. 11:171-88, 1971.

Louis-Ferdinand, R.T., and Fuller, G.C.: Rate assay for estimation of thiol affinity of sulfhydryl reactive reagents. Estimation of sulfhydryl reactivity. J. Pharm. Sci. 58(9): $1155-57,1969$.

Louis-Ferdinand, R.T., and Fuller, G.C.: The mechanism of the biological activity of a series of nitroolefins. Tox. App1. Pharmaco1. 16:668-74, 1970 .

Louis-Ferdinand, R.T.: in MS. thesis, University of Rhode Island, 1968.

Lehninger, A.L.: Biochemistry. Worth Publishers Inc., New York, N.Y., 833 pps, 1970.

Mackworth, J.F.: The inhibition of thiol enzymes by lachrymators. Biochem. J. 42:82-90, 1946.

Muller, R.: The histochemical localization of phosphatases in A. Glabratus. Proc. Zoo. Soc. Lond. 144:229-36, 1963. 
Nabih, I., and Metri, J.: Structure and activities in molluscicides III: enzymatic peroxidation of the molluscicidal agent pentachloropheno1. J. Pharm. Sci. 60:1242-43, 1971.

Nambara, T.: Some compounds related to vinyl sulfone and their bacteriostatic and chemical activities. J. Pharm. Soc. Japan $74: 13-16,1954$.

Ochoa, S.: Malic dehydrogenase from pig heart. in: Methods in Enzymology (Colowick and Kaplan, ed.) 735-39, Academic Press, New York, 1955.

Peters, R.A., and Wakelin, R.W.: The splitting of some thioether linkages by silver salts under mild conditions. Biochem. J. 41:555-64, 1947 .

Peters, R.A., and Wakelin, R.W.: The toxicity of vesicants and some other compounds to the pyruvate oxidase system.(brain). Brit. J. Pharmaco1. 4:51-62, 1949.

Pfleiderer, G., and Auricchio, F.: The DPNH-binding capacity of various dehydrogenases. Biochem. and Biophys. Res. Comm. 16 (1):9-16, 1964 .

Picken, L.E.R.: The mechanism of urine formation in invertebrates. J. Ex. Biol. 14:20-34, 1937.

Potts, W.T.: Excretion in the molluscs. Biol. Rev. 42:1-41, 1967.

Potts, W.T.: Aspects of excretion in the molluscs. in: Studies in the structure, physiology, and ecology of molluscs (Vera Fretty, ed). Academic Press, London, pg 187-91, 1968.

Ramakrishna Karup, K.C., and Sanadi, D.R.: Sulfhydryl involvement in the energy transfer pathway. Biochem. 7(12):4483-91, 1968.

Reitman, S., and Franke1, S.: A colorimetric method for the determination of serum glutamic oxalacetic and glutamic pyruvic transaminases, Am. J. Clin. Path. 28:56-61, 1957.

Rosenthal, H.L.: Determination of urea in blood and urine with diacetyl monoxime. Ann. Chem. 27:1980-85, 1955.

Smuth, H.F., Carpenter, C.P., Weil, C.S., Pozzani, U.C., and Striege1, J.A.: Range finding toxicity data: List VI. Am. Ind. Hygiene Assoc. J. 23:95-107, 1962.

Solberg, L.A., and Forte, J.G.: Differential effects of sulfhydryl reagents on transport and electrical properties of gastric mucosa. Am. J. Physio1. 220:1404-12, 1971. 
Watkins, Dudley, S.J., Cooperstein, and Lazarow, A.: Effect of sulfhydryl reagents on permeability of toadfish islet cells. Am. J. Physiol. 219:503-09, 1970.

Watkins, W.M., and Wormall, A.: Action, in vitro, and in vivo, of some nitrogen mustards on hemolytic complement. Biochem. J. $52: 365-77,1952$.

Webb, J.L.: Enzyme and metabolic inhibitors. Academic Press, New York, N.Y., 687 pps, 1966.

Welnbach, E.C.: Studies on the intermediary metabolism of the aquatic snail, A. glabratus, Arch. Biochem. Biophys. 42:231-44, 1952.

W.H.O.: Monograph series number 50, World Health Organization, Geneva, pg 11, 1965.

Wright, C.A., File, S.K., and Ross, G.G.: Studies on the enzyme system of planorbid snails. Ann. Trop. Med. and Parasit. $60: 522-25,1967$.

Yuki, H., Sano, F., Takama, S., and Suzukin, S.: Relation between activity of sulfhydryl reagents and their inactivating activity of adenovirus type v. Chem. Pharm. Bull. (Tokyo), $14(2): 139-46,1966$.

Zsolnai, T.: The molluscicidal action of thiol reagents. $Z$. Bakterio1. Parasitenk Infektion Nskrankh Hyg. Abt. I Orig. $213: 270-83,1970$. 


\section{VITA}

Paul T. La Rocca was born in Weehawken, New Jersey on March 15, 1946. He received his grammar school education at St. Mary's School, Dumont, N.J. and his high school education at Bergen Catholic of Oradell, New Jersey. After graduating from St. John's University, School of Pharmacy, he completed his pharmacy internship at Morse Pharmacy, Closter, N.J.. On completion of his internship, he accepted a teaching position at Abeel School where he taught for the last five months of the school year. He then worked at La Rocca Laboratories until September, 1970, when he began full time graduate education at the University of Rhode Island. He is married to the former Mary Anne Kunz of Haworth, New Jersey. He is a licensed pharmacist and a member of Sigma $\mathrm{Xi}$. 